\title{
Strain dependent variation of microstructure and texture in naturally deformed Carrara marble
}

\author{
Nils Oesterling ${ }^{\mathrm{a}, 1}$, Renée Heilbronner ${ }^{\mathrm{a}}$, Holger Stünitz ${ }^{\mathrm{a}, *}$, \\ Auke Barnhoorn ${ }^{\mathrm{b}, \mathrm{c}}$, Giancarlo Molli ${ }^{\mathrm{d}}$ \\ ${ }^{a}$ Department of Geosciences, Basel University, Bernoullistr. 32, CH-4056 Basel, Switzerland \\ ${ }^{\mathrm{b}}$ Geological Institute, ETH-Zentrum, CH-8092 Zurich, Switzerland \\ ${ }^{\mathrm{c}}$ Research School of Earth Sciences, The Australian National University, Canberra, A.C.T. 0200, Australia \\ ${ }^{\mathrm{d}}$ Dipartimento di Scienze della Terra, Università di Pisa, I-56126 Pisa, Italy
}

Received 31 March 2006; received in revised form 24 October 2006; accepted 27 October 2006

Available online 22 December 2006

\begin{abstract}
This study investigates the microstructure and texture variations across a mm-scale shear zone in Carrara marble of the Alpi Apuane (Italy). The microstructures have been investigated for grain size, texture, and shape fabrics. Textures have been measured with Computer-Integrated Polarization Microscopy (CIP) and Electron Back Scattered Diffraction (EBSD) separating porphyroclast and recrystallized grains. The deformation, which post-dates an earlier deformation phase and subsequent annealing, is strongly localized. The microstructures and textures change across the shear strain gradient and are interpreted to preserve a time sequence of progressive stages of deformation. The bulk shear strain rate is estimated to be about $10^{-11} \mathrm{sec}^{-1}$ at deformation temperatures of approximately $325^{\circ} \mathrm{C} \pm 30^{\circ} \mathrm{C}$.

The protomylonite is characterized by a core mantle structure with a bimodal grain size distribution which changes gradually to a completely dynamically recrystallized microstructure with a unimodal grain size distribution in the mylonitic center of the shear zone. Core-mantlestructures are produced by dominant rotation recrystallization accompanied by some grain boundary migration. The microstructural transition from protomylonite to mylonite coincides with a change in texture. With increasing strain the single c-axis maximum of an earlier inherited texture in the protomylonite is replaced by a similar texture in a different orientation (maximum normal to the shear plane) which is consistent with dominant basal $\langle a\rangle$ and $r\langle-2201\rangle$ slip. The microstructural and textural variations depend on the proportion of recrystallized grains. As dynamic recrystallization progresses with finite strain the texture development is finite strain-dependent. The comparison of the microstructures and textures to other natural and to experimental examples explains the progressive change of the texture and demonstrates the texture evolution produced by dynamic recrystallization.
\end{abstract}

(C) 2006 Elsevier Ltd. All rights reserved.

Keywords: Calcite deformation; Carrara marble; Shear zones; Dynamic recrystallization; Crystallographic preferred orientation; Image analysis

\section{Introduction}

The development of microstructures, shape fabrics, and textures (crystallographic preferred orientation, CPO) during progressive deformation is an important topic in structural

\footnotetext{
* Corresponding author. Tel.: +4161267 3596; fax: +41612673613.

E-mail address: holger.stuenitz@unibas.ch (H. Stünitz).

${ }^{1}$ Present address: Bundesamt für Landestopografie, Landesgeologie, Seftigenstrasse 264, CH-3084 Wabern, Switzerland.
}

geology because much of our interpretation and reconstruction of rock deformation history is dependent on such information. The progressive development of deformation fabrics can be studied directly in analogue "see-through" experiments (e.g. Herwegh and Handy, 1998; Burg and Wilson, 1987; Means, 1983; Wilson, 1981). Another way to study fabric development is to perform rock deformation experiments to different finite strains under constant $\mathrm{P}, \mathrm{T}$, and strain rate conditions and measure the textures and microstructural parameters (i.e. grain size and grain shape) as a function of increasing finite 
bulk strain (for calcite see, e.g., Barnhoorn et al., 2004; Pieri et al., 2001a,b; Rutter, 1995; Schmid et al., 1987).

In order to study fabric development in nature, certain conditions have to be met or certain assumption have to be made, because natural deformation only leaves an end product at a certain finite strain. Some shear zones with finite strain gradients may provide a record of progressive deformation under conditions, where a single or several physical parameters (e.g. T, P, stress, strain rate) can be demonstrated to be constant. However, the most important assumption to be made in such cases is that the strain gradient reflects a preserved time sequence of the stages of the deformation, i.e., that the strain variations are due to the spatial localization of the deformation in certain portions of the shear zone. This situation is given if the shear zones narrows with time (type 2 shear zone of Means, 1995).

In this study, we are analysing the microstructures and textures of a natural shear zone in Carrara marble. The observed fabric differences and the strain gradients are interpreted in terms of a development in time as the shear zone has narrowed and deformation has become localized.

Carrara marble is a good example for such studies. It has been regarded as a completely annealed, relatively fine grained (in comparison to Yule marble), randomly textured, pure calcite marble which is why it has been used for many experimental studies of calcite deformation. However, over the past years, regional structural studies in the Alpi Apuane have shown that there is substantial deformation that postdates the annealing phase so that numerous shear zones and folds can be found, which display dynamic microstructures (Molli et al., 2000; Molli and Heilbronner, 1999). Such structures are well suited examples to study localized calcite deformation, because they overprint rather isotropic microstructures.

There are a number of studies concerning the development of microstructure and texture in natural calcite shear zones under a range of temperature, strain and/or strain rate conditions (e.g. Behrmann, 1983; Bestmann et al., 2000; Busch and Van der Pluijm, 1995; de Bresser, 1989; Dietrich and Song, 1984; Erskine et al., 1993; Heitzmann, 1987; Schmid, 1981; Van der Pluijm, 1991). The largely consistent microstructural and textural variations of these studies are compared with our observations and interpretations and with experimental data (Wagner et al., 1982; Schmid et al., 1987; Rutter et al., 1994; Casey et al., 1998; Pieri et al., 2001a,b; Wenk, 2002; Barnhoorn et al., 2004) in order to produce a consistent picture of an example of a progressive development of microstructure and texture in a calcite shear zone.

Such an interpretation of fabric development with progressive deformation and recrystallization can be particularly important for texture studies, because dynamic recrystallization has only recently been incorporated in texture simulations (Wenk et al., 1987; Wenk and Tomé, 1999; Wenk, 2002) and is a yet poorly understood aspect of texture development. Furthermore, twinning, pressure solution, and grain boundary sliding also contribute to the fabric development in calcite mylonites (Schmid, 1975; Burkhard, 1990; Schmid et al., 1987; Busch and Van der Pluijm, 1995; Kennedy and White, 2001) to an extent that is difficult to quantify in models. Thus, natural examples of heterogeneous finite shear strain may provide insight to texture development. The present study is attempting to contribute to the understanding of calcite fabric development.

\section{Geological setting and regional geology}

Carrara marbles are part of the lower to middle Liassic carbonate platform sequence of the former Italo-Adriatic continental margin which was deformed and metamorphosed under greenschist facies conditions during the Apennine orogeny. These metamorphic rocks are exposed in the Alpi Apuane tectonic window in northern Tuscany, Italy.

Two deformation events can be distinguished in this area (Carmignani et al., 1994; Carmignani and Giglia, 1979; Carmignani and Kligfield, 1990; Molli et al., 2000). The main deformation event (D1) has started in Late Oligocene times (25-27 my) as part of a crustal shortening regime. A second deformation event (D2) has begun in the Early Miocene (12-14 my) as the result of crustal extension (Kligfield et al., 1986). During the early stage of D1, regional scale isoclinal folds were generated with inclined axial planes dipping to the SW (Fig. 1). Folding terminated in conjunction with a thermal event which caused an annealing of all dynamic microstructures. During the later part of the D1-history, deformation was localized in discrete shear zones which overprinted the annealed microstructures (Molli et al., 2000). The nappe stacking at the end of the first deformation event produced an antiformal stack geometry.

The nappe stack was extended during D2, when open folds with sub-horizontal axial planes and micro-scale shear zones developed (Fig. 1). Folding is restricted to lithologically heterogeneous sequences such as the middle to upper Liassic cherty limestone, which is composed of alternating layers of quartzite and impure limestone. Small-scale shear zones occur mainly in the pure and homogeneous calcite marble (Carrara marble). Vergence of minor folds as well as the shear sense indicators are directed top to the SW on the SW-side of the culmination of the Alpi Apuane and top to the NE on the NE-side of the culmination. A detailed description of the macro- and mesoscopic deformation structures and related microstructures can be found in Coli (1989), Molli et al. (2000) and Molli and Heilbronner (1999).

\section{Shear zone and sample description}

The shear zone analyzed in this paper formed during D2 and was sampled in the upper part of the Frigido valley in

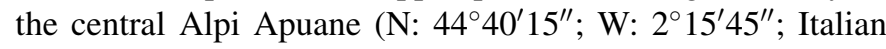
coordinate system) (box in Fig. 1). This region is characterized by a large D2-fold structure which refolds the regional scale D1-Vinca-Forno anticline (Boccaletti et al., 1982; Carmignani, 1985). During the initial stage of D2-folding the overturned limb of the D1-fold, which generally dips to the SW, is overprinted by a reactivated pre-existing fault (Monte Rassori fault, indicated in Fig. 1) to such an extent that, locally, the 


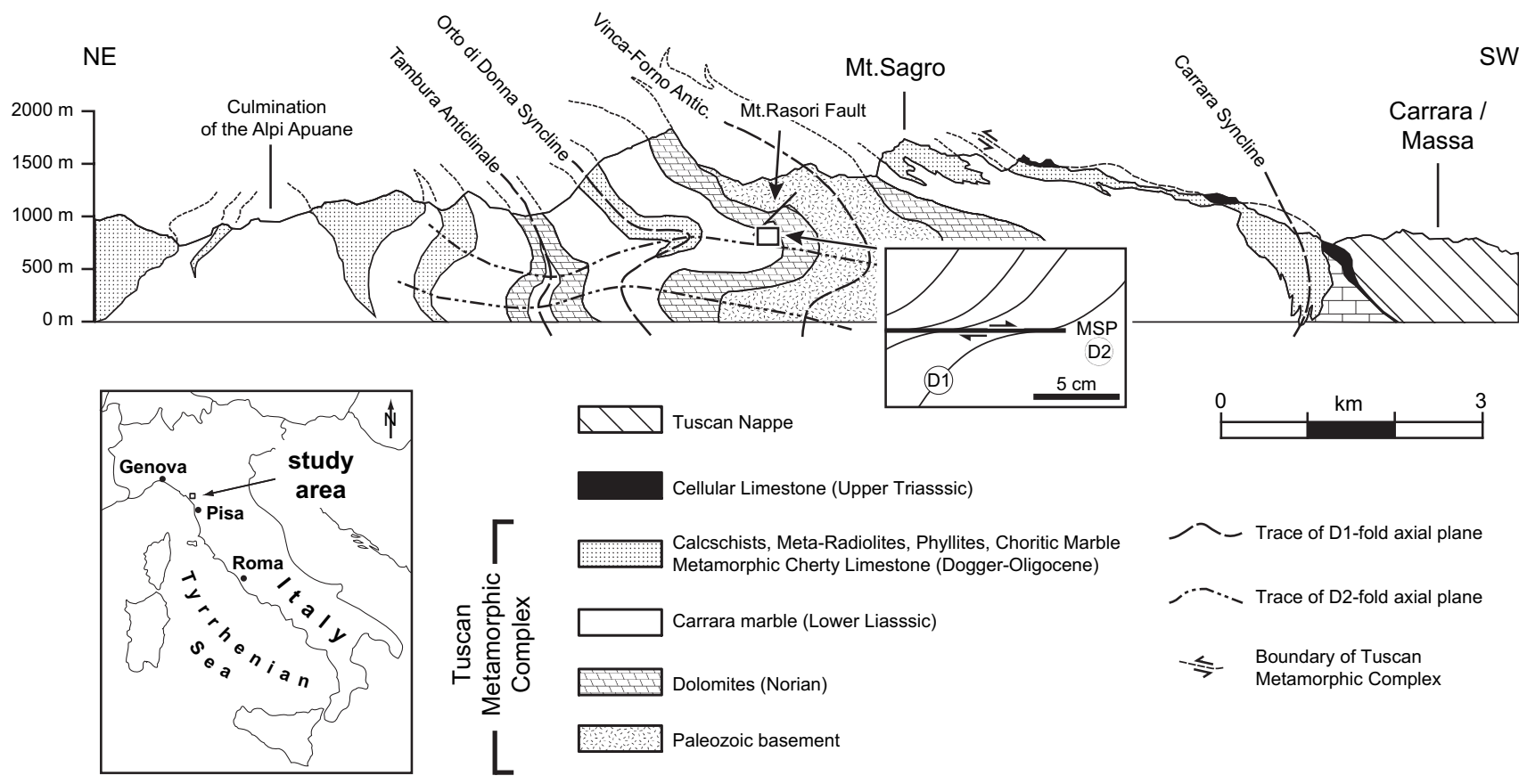

Fig. 1. Schematic geological cross section and stratigraphic section of the Alpi Apuane tectonic window (modified after Carmignani and Giglia, 1979). The sample location is marked by the rectangular box. The details in the box show the orientation of the median shear plane (MSP) of the D2 shear zone and the S1 layering. Note that the section is oriented with NE at the left.

tight S1-foliation and layering are re-oriented causing them to dip to the NE in the vicinity of the analyzed sample.

The shear zone under consideration is located in Liassic marble (Carrara marble). The shear plane (SP), defined by the shear zone boundary, is parallel to the sub-horizontal axial plane of the D2-fold. The shear zone length is less than $10 \mathrm{~cm}$ when measured along the SP, and significant deformation is confined to the central $5 \mathrm{~mm}$ wide zone (Fig. 2a). A topto-the-SW sense of shear is indicated by the re-orientation of the pre-existing calcite and dolomite layers in the vicinity of the shear zone which are otherwise parallel to the axial planes of isocline D1-folds (S1). The layering (Fig. 2a) is easily visible in hand specimen by the color contrast of creamy yellow impure dolomite (with some calcite; grey in Fig. 2a) and white pure calcite. The shear zone is symmetric about the central plane displaying the geometry of a ductile shear zone (Ramsay and Graham, 1970) of heterogeneous shear with the highest shear strain values in the center. Laterally the shear zone grades into a discontinuity, where the offset of S1 remains constant, but bending of $\mathrm{S} 1$ is absent. As no stretching lineation can be observed, the sample has been cut mutually perpendicular to the maximum curvature of the deformed S1 foliation and the SP in order to undertake the detailed study.

This study focuses on the strain gradient of the shear zone from which seven regions were examined at various distances from the shear plane (Fig. 2a). Only the microstructures and textures of a pure calcite layer are investigated. Optical microstructures provide a framework for the detailed study. There is a continuous increase of recrystallized material in the pure calcite marble outside the shear zone (protomylonite) with an estimated $30-80$ vol.\% recrystallized grains to the central calcite mylonite with $100 \mathrm{vol} \%$ recrystallized grains (Fig. 2b). Mylonite is used for microstructures with more than $80 \%$ recrystallized grains (this nomenclature deviates from that of Sibson (1977), because we observe significant changes in the textures and microstructures between sites 4 and 6 and use the different terms mylonite and protomylonite to denote these changes).

In the protomylonite distinct core-mantle microstructures are pre-dominant and porphyroclasts and recrystallized grains co-exist (Fig. 3). Porphyroclasts have lobate grain boundaries and subgrains of the same size as the recrystallized grains, which surround them. Twins with serrated or irregular boundaries are common. The recrystallized grains are isometric and internally strain free; they display neither undulatory extinction, twins, nor subgrains (Fig. 3).

\section{Methodology}

\subsection{Microstructural analysis}

Microstructures were studied using light and electron microscopy in conjunction with analysis of digitally acquired images. Digital micrographs and c-axis orientation images calculated by the Computer-Integrated Polarization Microscopy (CIP method, software available at [1]: Panozzo Heilbronner and Pauli, 1993; Heilbronner, 2000) were used as a basis for image analysis. The grain outlines were traced manually directly on the digital images. The same magnification using a constant resolution of 1 pixel $=0.35 \mu \mathrm{m}$ was maintained for all images. Grain size is analyzed by measuring grain sectional areas (NIH-Image [2]) and calculating 
(a)

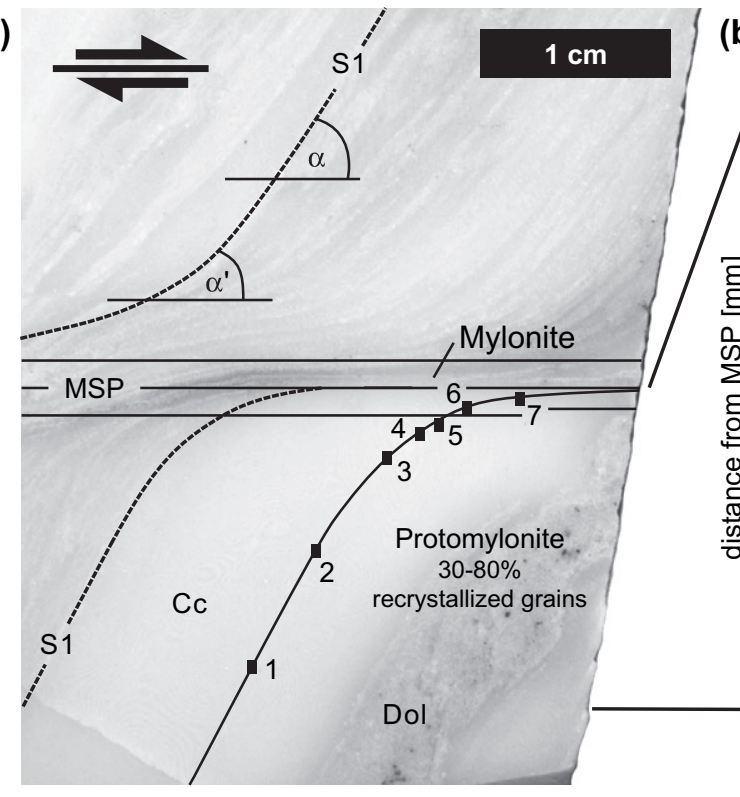

(b)

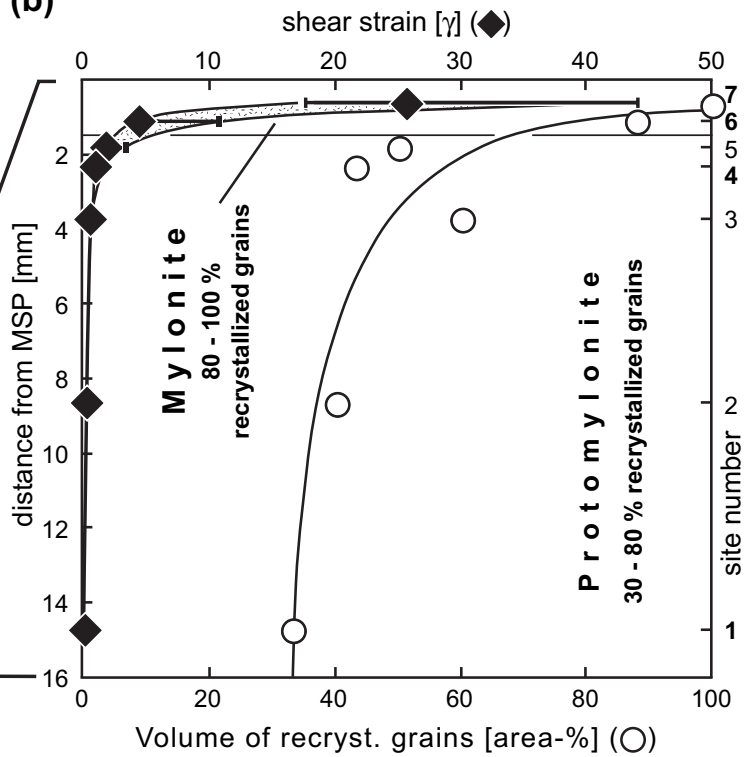

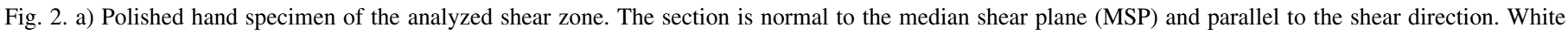

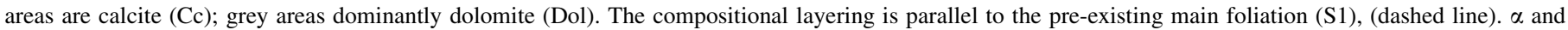

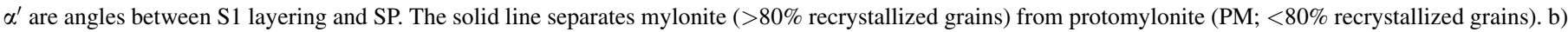

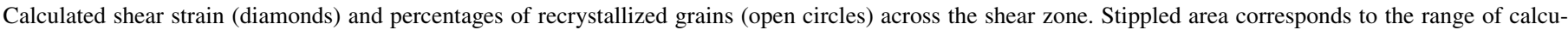

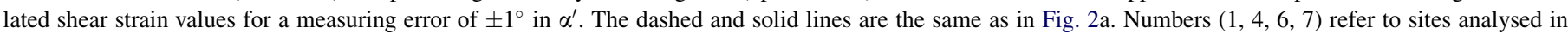
detail. Curves are visual best fits to data and highlight individual data sets.

both the diameters of the equivalent circles $(d e)$ and the size distributions $\mathrm{h}(d e)$, of the latter. The distribution of grain volumes is calculated from the numerical densities of equivalent diameters, $\mathrm{h}(d e)$, within grain sections in terms of the volumetric densities of the diameters of the equivalent spheres, $\mathrm{V}$ (D) (Fig. 5), where $\mathrm{D}$ is the diameter of a volume-equivalent sphere and $\mathrm{V}$ is the volume percentage of a given size class. For the conversion from 2-D to 3-D grain sizes we used the program StripStar [1] based on the Schwartz-Saltykov approach (Underwood, 1970). Detailed information on the application can be found in Heilbronner and Bruhn (1998).

Shape factors of grains were determined by first vectorizing the outlines of the grain boundary maps (Ime d'Ouline [1]). The particle and surface parameters were determined using the PAROR and SURFOR methods (Panozzo, 1983, 1984); software are available at [1]. The long and short axes of the individual grains were derived and rose diagrams representing the orientation distribution functions (ODFs) of particle long axes and grain boundary segments were plotted (Fig. 5). Using the projection curves $\mathrm{B}(\alpha)$ (Fig. 6) derived with the PAROR program (Panozzo, 1984), the bulk fabric anisotropy in the form of an axial ratio (b/a), and the angle of the preferred orientation of the fabric ( $\alpha p)$ was determined.

The lobateness (convexity/concavity) of grain boundaries was quantified using the PARIS factor (percentage of the average relative indented surface fraction) as described by Panozzo and Hürlimann (1983). A PARIS factor of 0\% signifies a strictly convex shape while increasing values signify increasing lobateness; there is no upper limit to the value of the PARIS factor. Separate PARIS factors for the recrystallized grains and for the porphyroclasts are shown in Fig. 8. In order to examine crystallographic preferred orientations (CPO), the c-axes distribution was determined using Computer-Integrated Polarization Microscopy, the CIP method, (Panozzo Heilbronner and Pauli, 1993; Heilbronner, 2000) and the complete crystallographic orientation was determined using electron back scattered diffraction (EBSD). The results are shown in Fig. 9. To ensure the closest possible coincidence of the sites sampled for CIP and EBSD, the part of the specimen chip opposite to the optical thin section was used for EBSD measurements.

The EBSD system comprised a CamScan CS44LB with a spot size set to $100 \mathrm{~nm}$. Points measured on grain boundaries yielded low confidence indices $(\mathrm{CI}<0.2)$ and were excluded. For the calculation of pole figures (e.g. Fig. 9), more than 15,000 measurements were used. The CIP method calculates area-weighted (i.e., volume-weighted) c-axis pole figures. By masking the appropriate part of the image, partial pole figures for recrystallized grains and porphyroclasts can be calculated separately (Fig. 10) with the pole figures of the larger grains representing the "pure" CPO of porphyroclasts.

In Figs. 9 and 10, the maxima of the pole figures are not indicated, because the evaluated area is too small for a statistically meaningful evaluation. Even though the number of evaluated pixels (by CIP) is large, the number of grains per analyzed section, i.e., the number of independent measurements may be small. As a consequence, the resulting pole figures display many single crystal orientations with highly exaggerated maxima. However, for the purpose of this study these artefacts present no problem because the main interest here is the symmetry - not the absolute density - of the pole figures. 

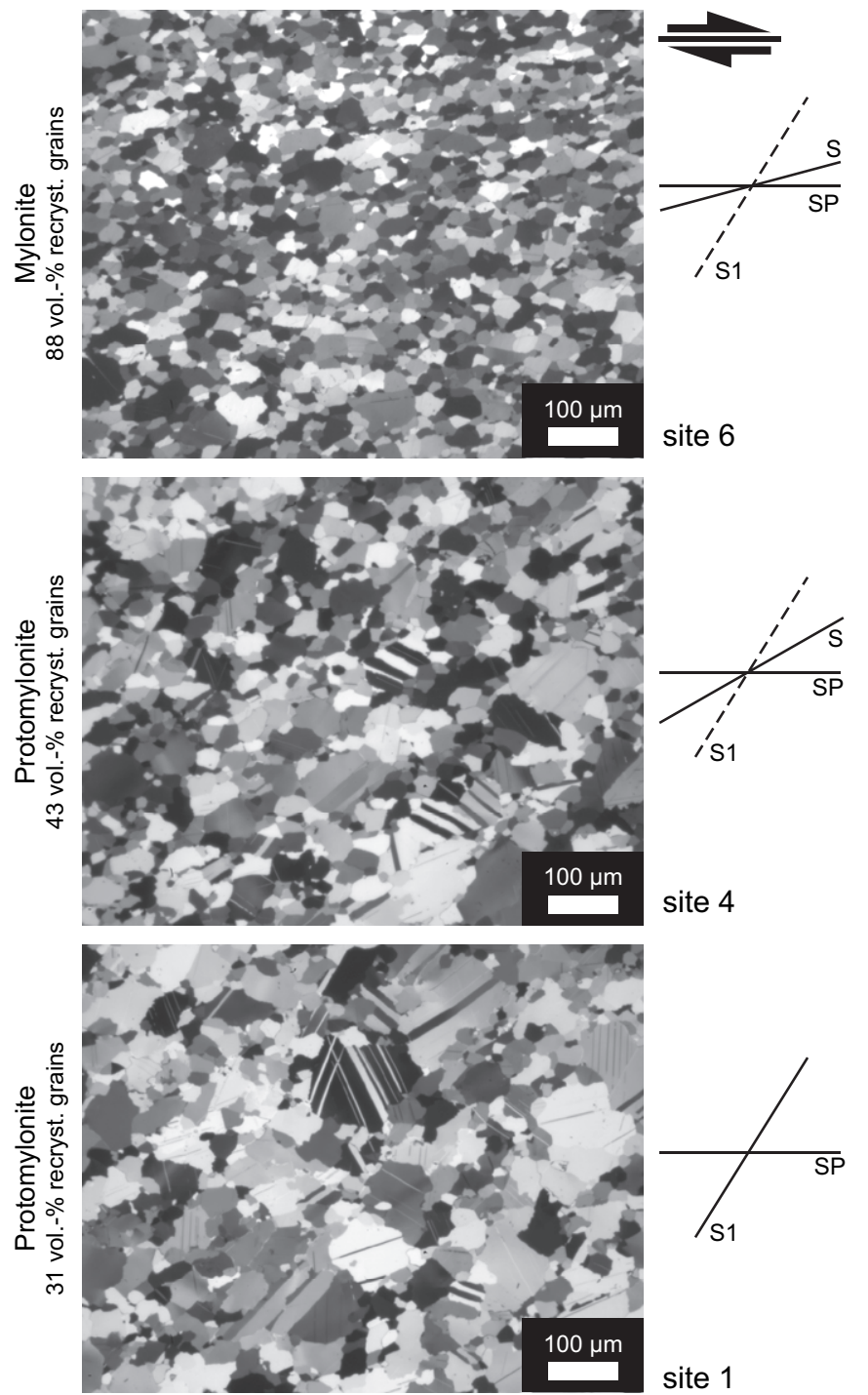

Fig. 3. Characteristic microstructures of protomylonite with $31 \%$ recrystallized grains (site 1), protomylonite with $43 \%$ recrystallized grains (site 4 ) and mylonite with $88 \%$ recrystallized grains (site 6). The D2 shear plane (SP) is horizontal, the sense of shear is dextral. The orientation of the main foliation in the lowest strain sample (S1 at site 1) is indicated, and the progressively rotated $\mathrm{S} 1$ at the other sites is termed $\mathrm{S}$.

\subsection{Temperature determination}

The deformation temperature of the analyzed shear zone was determined using calcite-dolomite thermometry. Below the temperature range of $500-800{ }^{\circ} \mathrm{C}$ the calcite-dolomite solvus curve has a steep slope, so that potential errors in the temperature determination may arise (Anovitz and Essene, 1987). However, the system is applied widely with consistent results at lower temperatures (Anovitz and Essene, 1987, and references therein). A prerequisite for successful application is that recrystallization of the phases takes place to facilitate cation equilibration at temperatures below about $500{ }^{\circ} \mathrm{C}$ (Matthews et al., 1999). In the analyzed shear zone, evidence of dynamic recrystallization of calcite is clear, and dolomite/ calcite phase boundaries are lobate indicating phase boundary mobility. Consequently, cation equilibration can safely be assumed for the recrystallized microstructures (see sample description) and the application of calcite-dolomite thermometry appears appropriate.

The Mg- and Fe-content were measured in calcite and dolomite pairs located in a calcite-dolomite layer adjacent to the investigated calcite layer (SP, Fig. 4). Rims of dolomite grains and their immediately adjacent calcite matrix were analyzed. A JEOL 8600 microprobe at an acceleration voltage of $12 \mathrm{kV}$, a beam size of $1 \mu \mathrm{m}$, and a beam current of $7 \mathrm{nA}$ was used in conjunction with natural standards, counting times of 10-20 s and a ZAF correction. The temperatures were calculated after Anovitz and Essene (1987), who use the Mg- and $\mathrm{Fe}$ - content in calcite according to a ternary solution model for the determination of the deformation temperature. Powell et al. (1984) have introduced a correction for Fe-content in calcite and dolomite. Because of the very low Fe-content measured in calcite and dolomite $(\mathrm{XFe} \mathrm{Cc}<0.006$; XFe Dol $<0.02)$ in the analyzed sample we have used the thermometer of (Anovitz and Essene, 1987) without any Fe-correction. The measurements are listed in Table 1; error bars are the standard deviation of the respective measurements.

\section{Results}

\subsection{Shear strain}

The shear strain at any given distance from the central plane is calculated using the equation (Ramsay, 1967):

$\gamma=\cot \alpha-\cot \alpha^{\prime}$

where $\gamma$ is the shear strain at the position of interest, $\alpha$ is the angle between the shear plane (SP), the undeformed markers (in this case $\mathrm{S} 1$ foliation) and $\alpha^{\prime}$ is the angle between SP and the deformed markers at the position of interest (Fig. 2a,b). With increasing distance from the center the shear strain asymptotically approaches zero and therefore the shear zone boundary is difficult to define. The total displacement across the shear zone, measured as the offset of layers, is $\sim 40 \mathrm{~mm}$ at a total shear zone width of $\sim 10 \mathrm{~mm}$. Thus, the shear zone shows an average bulk shear strain of $\gamma \approx 4$. In the fully recrystallized central mylonite part $\gamma$ is greater than 20 , whereas at site 3 in the protomylonite, $\gamma$ equals 0.4 (Fig. 2).

A major part of the shear zone discussed here is composed of the so-called protomylonite, i.e. of material which is dynamically recrystallized up to $80 \mathrm{vol} \%$, but with shear strains below $\gamma=2$. Shear strain values of $\gamma>2$ are found only in the mylonite, i.e., only within the central $2 \mathrm{~mm}$ of the shear zone. Closer to the central (symmetry) plane it is more difficult to determine the shear strain. The stippled area in Fig. $2 b$ shows the range of calculated shear strain values (using Eq. (1)) if a measuring error of $\pm 1^{\circ}$ for $\alpha^{\prime}$ is assumed. 


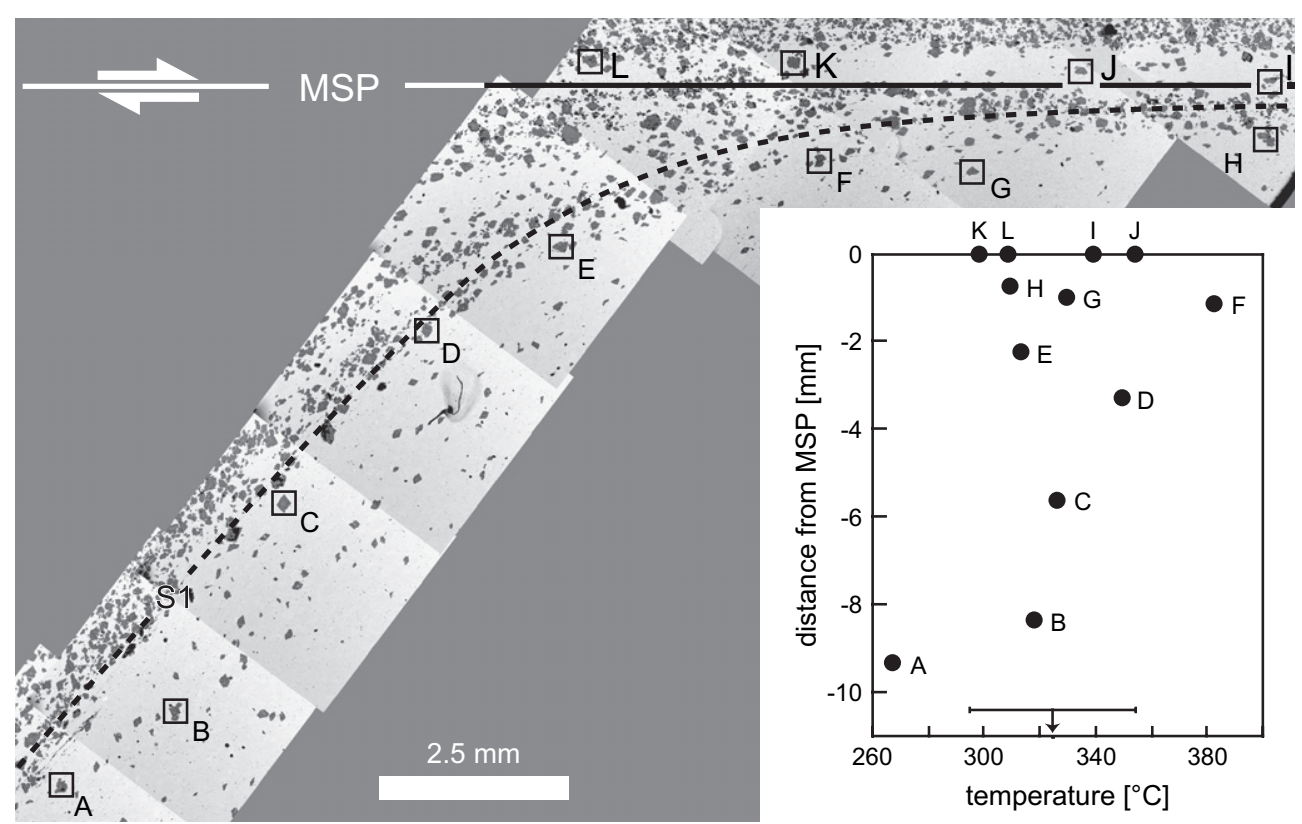

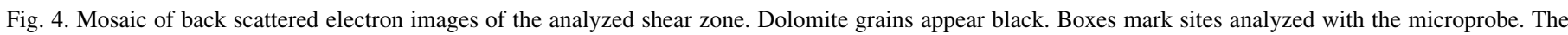

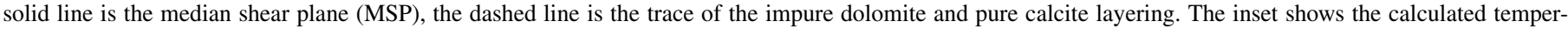
atures (Anovitz and Essene, 1987) for the analyzed sites, the average temperature and standard deviation is indicated as arrow and error bar, respectively.

\subsection{Deformation temperature}

The dolomite grains used for temperature determination are preferentially arranged along S1 layers (Fig. 4). The average temperature is $324 \pm 30{ }^{\circ} \mathrm{C}$ standard deviation; the total range of measured temperatures is $115^{\circ} \mathrm{C}$. The range of temperatures determined in the center of the shear zone is $56{ }^{\circ} \mathrm{C}$ (Table 1 , Site $\mathrm{I}-\mathrm{L}$ ) reflecting the large measuring error. Most values of the shear zone lie in this temperature range of the mylonite layer (Fig. 4). Any linear slope fit to the temperature measurements (using an $F$-test) proves to be statistically insignificant. Thus, the deformation temperatures, measured by applying the thermometer of Anovitz and Essene (1987), show no systematic trend from the median shear plane (SP) to the wallrock

Table 1

Temperature determination of the method of Anovitz and Essene (1987)

\begin{tabular}{lll}
\hline Site $^{\mathrm{a}}$ & Distance from SP [mm] & Temperature \\
\hline $\mathrm{L}$ & 0.00 & 298 \\
K & 0.00 & 354 \\
$\mathrm{~J}$ & 0.00 & 307 \\
$\mathrm{I}$ & 0.00 & 338 \\
$\mathrm{H}$ & 0.07 & 308 \\
$\mathrm{G}$ & 0.11 & 381 \\
$\mathrm{~F}$ & 0.97 & 329 \\
E & 2.20 & 312 \\
D & 3.25 & 348 \\
C & 5.61 & 326 \\
B & 8.33 & 317 \\
A & 9.30 & 266 \\
Mean & & 324 \\
Std. Deviation & & 30
\end{tabular}

${ }^{\mathrm{a}}$ Location of measuring sites is shown in Fig. 4. rock (Table 1). Likewise, no temperature trend (Fig. 4) is discernible, neither parallel to SP nor along S1.

\subsection{Grain size distribution}

The protomylonite shows a broad grain size distribution ranging from diameters of 10 to $150 \mu \mathrm{m}$ (site 1, Fig. 5). There is one maximum at $30-40 \mu \mathrm{m}$ corresponding to the recrystallized grains, and a second one (at $120-130 \mu \mathrm{m}$ ) corresponds to the porphyroclasts (Fig. 5, site 1). The high frequency at $\sim 80 \mu \mathrm{m}$ is probably due to statistical scatter. With increasing strain, the porphyroclast mean grain size decreases and shifts towards smaller size classes while the volume of the recrystallized grains increases. Close to the shear zone center (site 7), the porphyroclasts are completely recrystallized. In the mylonite (site 6 and 7; close to 100\% recrystallization), the distribution is unimodal, and the recrystallized grain size is smaller $(\sim 20-30 \mu \mathrm{m})$ in the mylonite at the center of the shear zone than in the protomylonite ( 30-40 $\mu \mathrm{m}$; Fig. 5).

\subsection{Dynamic recrystallization and volume percentage of recrystallized grains}

The nature of core-mantle microstructures and the same size of subgrains and recrystallized grains indicate that progressive subgrain rotation is the dominant process of dynamic recrystallization in the shear zone. All grain- and some twin boundaries are slightly lobate and indicate that some local grain (and twin) boundary migration has accompanied subgrain rotation during recrystallization (Fig. 3). However, the migrating boundaries do not appear to sweep whole grains, 

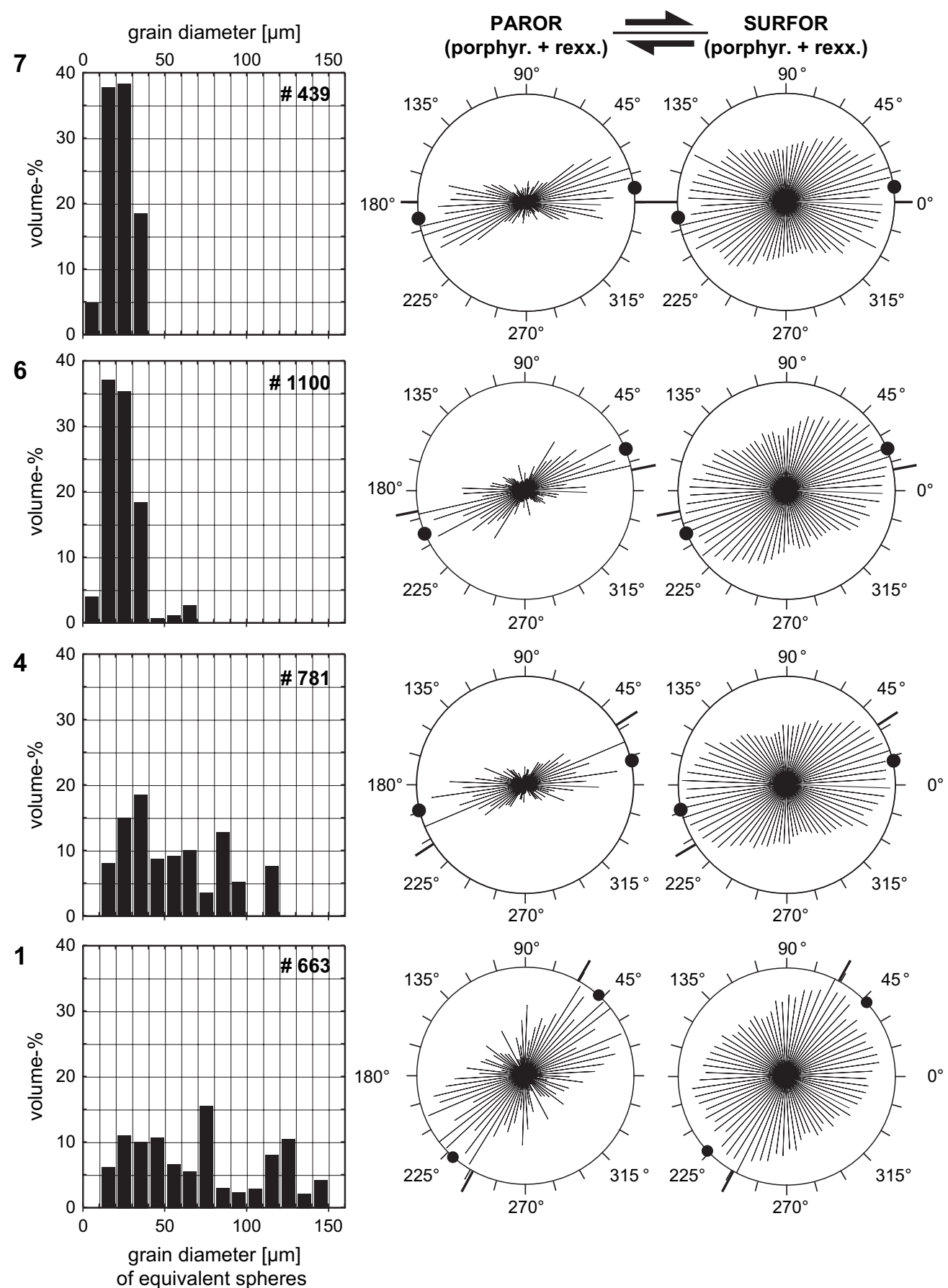

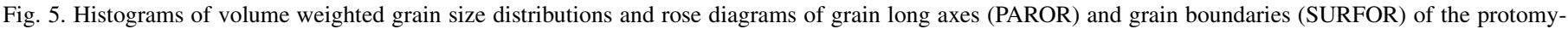

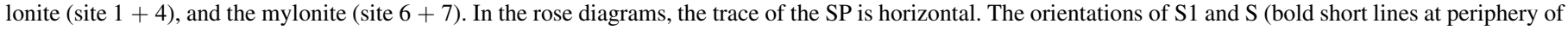

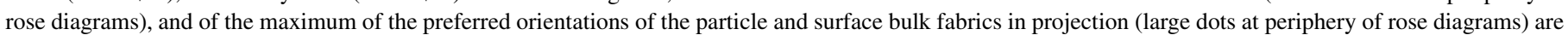
indicated.

so that boundary migration does not operate on a length scale of whole old grains (Guillopé and Poirier, 1979) and does not constitute grain boundary migration recrystallization as defined by Poirier and Guillopé (1979).

Using the area percentage of small grains, defined as $d e<40 \mu \mathrm{m}$, the volume proportion of recrystallized grains is estimated. Accordingly, the protomylonite contains $\sim 35$ vol. $\%$ recrystallized grains (site 1, Fig. 2 b), a value which can also be found in samples several meters away from the shear zone. The increase of recrystallized volume from $\sim 50 \%$ to $100 \%$ in the shear zone center occurs within the central 1 to $2 \mathrm{~mm}$. Between site 6 and 7 (at a shear strain of $\gamma \approx 10$ ), the mylonite is $100 \%$ recrystallized. With further increase of the shear strain $(\gamma \sim 25$; site 7, Fig. $2 b)$, the microstructure and the grain size distribution are the same as in site 6 indicating a steady-state microstructure. Below $\gamma \approx 5$, in the protomylonite, the increase in the amount of recrystallized grains is correlated with an increase in shear strain (Fig. 2b). 


\subsection{Preferred orientation of grain shapes and grain boundaries}

The orientations of particle long axes and grain boundary segments are represented in rose diagrams of Fig. 5. The S1 layering and foliation (at site 1, with increasing shear strain termed $\mathrm{S}$ at sites 4, 6; marked by bold short lines in rose diagrams, Fig. 5) is consistently rotated in a clockwise sense, the sense of overall shear, from $\sim 60^{\circ}$ with respect to the SP in the protomylonite at site 1 to near $0^{\circ}$ at the shear zone center (site 7, Fig. 5). The preferred orientation of the fabric ( $\alpha$ p, large dots in rose diagrams, Fig. 5) is determined from the projection curves of particles $\mathrm{B}(\alpha)$ and grain boundary surfaces $\mathrm{A}(\alpha)$ (for $\alpha p=90-\alpha$ min; Fig. 6), and do not exactly follow this trend of rotation. From site 1 to site 4 , ap of the particles determined by PAROR rotates clockwise from $48^{\circ}$ to $13^{\circ}$. From site 4 to site 6 , it rotates anticlockwise from $13^{\circ}$ to $23^{\circ}$, and from site 6 to site 7 clockwise again until $\alpha p$ is at an angle of $8^{\circ}$ at which point $\mathrm{S}$ is effectively parallel to the SP (Fig. 5).

The preferred orientations of the surface area fabric follow that of the particle fabric very closely, as is seen by comparing values of $\alpha$ p of particles and grain surfaces shown in Table 2 . The orientation distribution functions of the grain surface area (SURFOR rose diagrams on Fig. 5) of the protomylonite (site 1 ) is asymmetric with one maximum concentration approximately parallel to $\mathrm{S} 1$ and a second one parallel to the shear plane SP. At slightly higher shear strain (site 4), the surface ODF develops a single maximum at an angle approximately half way in between S1 and SP. At high strains (site 6), the maximum of surface ODF of the mylonite is at $23^{\circ}$ with respect to S. In the

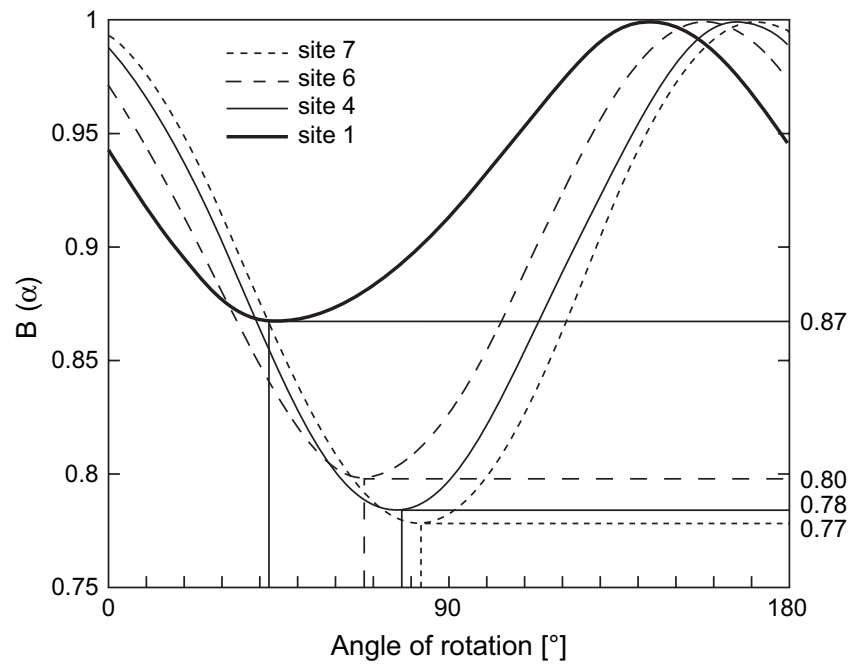

Fig. 6. Bulk fabric of protomylonite (site 1 and 4) and mylonite (site 6 and 7). The curve $\mathrm{B}(\alpha)$ represents the average particle projection (see PAROR; Panozzo, 1984). $\mathrm{B}(\alpha)$ is normalized: $\mathrm{B}(\alpha) \max =1.00$. The fabric anisotropy (b/a) is derived from the minimum: $\mathrm{b} / \mathrm{a}=\mathrm{B}(\alpha)$ min. The angle of preferred orientation $(\alpha p)$ is derived from the phase angle: $\alpha p=90^{\circ}-\alpha$ min where $\alpha$ min is the angle of rotation where $\mathrm{B}(\alpha)=\mathrm{B}(\alpha)$ min.

center of the shear zone (site 7, Figs. 2 and 5) the grain boundaries are aligned in a small angle $\left(8^{\circ}\right)$ to the SP, similar to the preferred orientation of the particle fabric (Fig. 5).

The average value of the axial ratios of the individual particles is $\mathrm{b} / \mathrm{a}=0.63$ and remains constant from the protomylonite to the mylonite. This is not in conflict with an increasing fabric intensity (Fig. 6), i.e., a decreasing bulk axial ratio b/a of the

Table 2

Microstructural results

\begin{tabular}{|c|c|c|c|c|c|c|c|}
\hline \multirow[t]{2}{*}{ Site } & \multirow{2}{*}{$\begin{array}{l}\text { Distance to } \\
\text { SP }[\mathrm{mm}]\end{array}$} & \multirow{2}{*}{$\begin{array}{c}\text { Orientation of } \\
\mathbf{S}\end{array}$} & \multirow{2}{*}{$\begin{array}{c}\text { Shear strain } \\
(\gamma)\end{array}$} & \multirow{2}{*}{$\begin{array}{l}\text { Area-\% } \\
\text { Recryst. }\end{array}$} & \multicolumn{2}{|c|}{ Mean-2D-grain size } & \multirow{2}{*}{$\begin{array}{l}\text { 3D-grain size } \\
\text { (Fig.5) }\end{array}$} \\
\hline & & & & & Porphyr. & Recryst. & \\
\hline 7 & 0.6 & 0 & $>20$ & 100 & - & 13.94 & 25 \\
\hline 6 & 1.1 & 10 & 4.7 & 88 & 47.4 & 15.78 & 25 \\
\hline 5 & 1.8 & 23 & 1.6 & 50 & 56.84 & 16.42 & - \\
\hline 4 & 2.3 & 33 & 0.8 & 43 & 58.76 & 20.86 & 35 \\
\hline 3 & 3.7 & 43 & 0.4 & 60 & 56.12 & 17.26 & - \\
\hline--- & --- & ----- & ----- & --- & ---- & ---- & ------ \\
\hline 2 & 8.6 & 55 & 0.1 & 40 & 60.34 & 17.78 & - \\
\hline 1 & 14.7 & 61 & 0 & 31 & 61.2 & 15.12 & 35 \\
\hline \multirow[t]{2}{*}{ Site } & \multicolumn{2}{|c|}{ SURFOR (Fig.5) } & \multicolumn{2}{|c|}{ PAROR (Fig. 5, 6) } & \multicolumn{2}{|c|}{ PARIS (\%) (Fig.7) } & No. of \\
\hline & $\mathbf{A}(\alpha \min )$ & $\alpha p$ & $B(\alpha \min )$ & $\alpha p$ & Porphyr. & Recryst. & Measure. \\
\hline 7 & 0.81 & 8 & 0.77 & 8 & - & 1.68 & 466 \\
\hline 6 & 0.81 & 23 & 0.80 & 23 & 12.8 & 1.74 & 645 \\
\hline 5 & 0.81 & 18 & 0.79 & 18 & 15.7 & 1.36 & 768 \\
\hline 4 & 0.80 & 13 & 0.78 & 13 & 16.4 & 1.8 & 840 \\
\hline 3 & 0.81 & 13 & 0.80 & 13 & 12.7 & 1.64 & 819 \\
\hline \multicolumn{8}{|c|}{ - - - - - - - - - - - - - - - - - - - - - - - - - - - - - - - - - - } \\
\hline 2 & 0.85 & 8 & 0.84 & 13 & 15.6 & 1.72 & 1003 \\
\hline 1 & 0.89 & 43 & 0.87 & 48 & 23.7 & 2.73 & 707 \\
\hline
\end{tabular}

Solid line separates protomylonite from mylonite; Dashed line marks the shear zone boundary. 

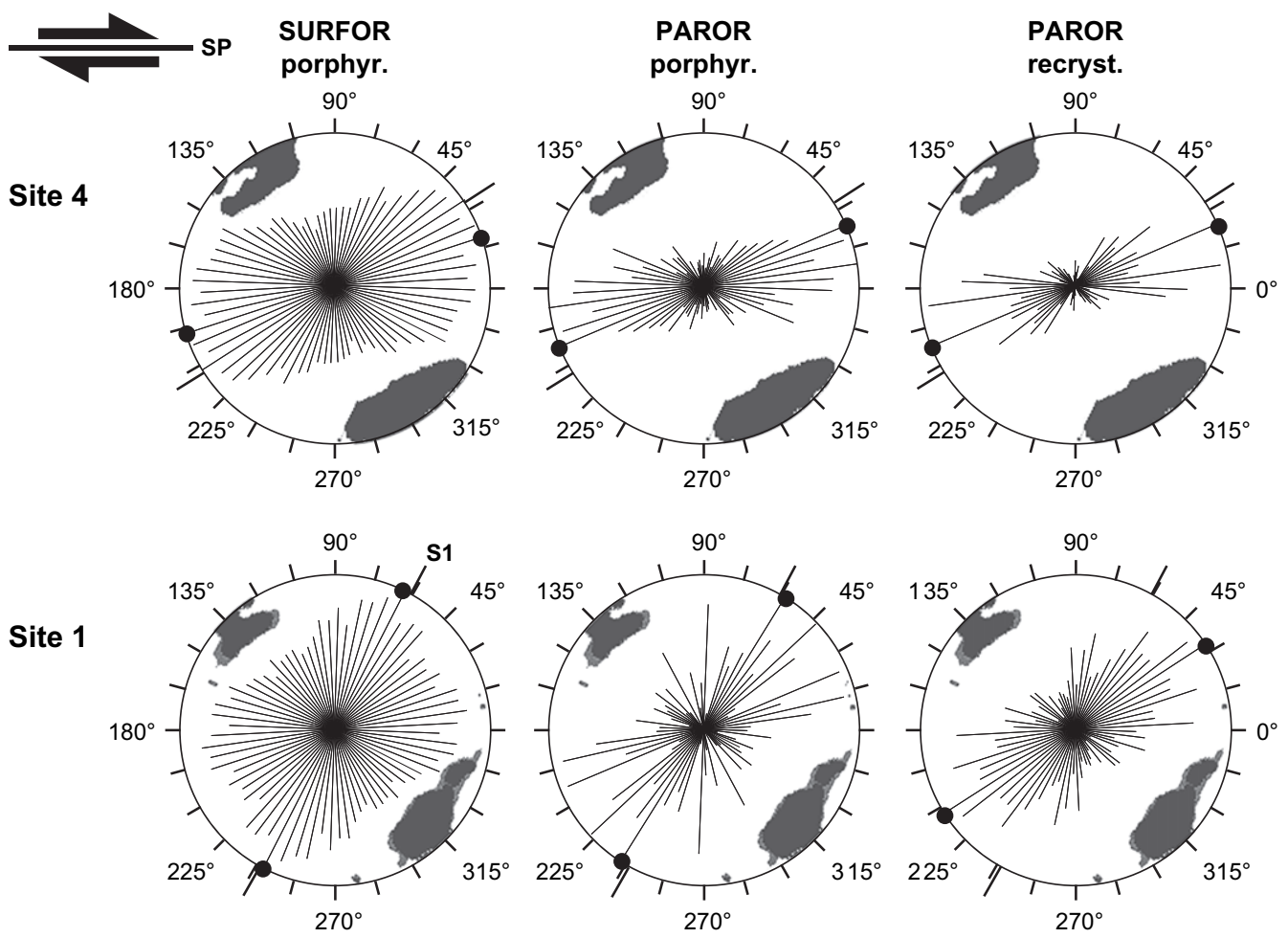

Fig. 7. Separate rose diagrams of grain long axes (PAROR) for porphyroclasts (middle) and recrystallized grains (right) for sites 1 and 4 . The rose diagram of grain surfaces (SURFOR) of porphyroclasts is shown on the left side. High density regions ( $>4$ times uniform) of the bulk c-axis pole figure are superimposed on the rose diagrams.

entire fabric from 0.87 in the protomylonite to 0.78 in the mylonite (decrease of $\mathrm{B}(\alpha)$ min in Fig. 6), because the axial ratio (anisotropy) of the fabric as a whole depends on both, the individual axial ratio of the particles (grains) and the intensity of the alignment of the particle long axes. The effect of a decreasing dispersion of the ODF can be seen in the PAROR rose diagrams (Fig. 5) from site 1 to 7 where particles with constant aspect ratios are becoming more closely aligned with the SP as recrystallization progresses. In two cases separate PAROR and SURFOR analyses of recrystallized grains and porphyroclasts were carried out; results for site 1 and 4 are shown in Fig. 7. At site 1, the particle preferred orientation of the recrystallized grains is rotated in a clockwise sense with respect to that of the porphyroclasts, at site 4 they are parallel. The surface fabric of the porphyroclasts is parallel to $\mathrm{S} 1$ and to the bulk fabric at site 1 (being dominated by the stronger maximum of the bimodal surface ODF), but rotates in advance of $S$ (in a clockwise sense) at site 4 .

\subsection{Grain shape analysis}

The PARIS-factors for grain shapes of recrystallized grains and porphyroclasts were determined separately. Along a profile from the edge to the center of the shear zone (Fig. 8), the recrystallized grains show a constant value for the PARISfactors of $\sim 2 \%$ indicating that the recrystallized grains are strongly convex. In contrast, the PARIS-factor of the porphyroclasts decreases towards the shear zone center (from 23 to
$13 \%$ ) indicating that the shape of the porphyroclasts is more concave initially and becomes progressively less concave (less lobate) as recrystallization progresses.

\subsection{Crystallographic preferred orientation}

The c-axis pole figures measured by the CIP method, and the EBSD pole figures of c-, r- and a-axes are shown in Fig. 9 together with pole figures from experimentally deformed calcite (Schmid et al., 1987; Barnhoorn et al., 2004) included for comparison. For site 4, separate pole figures were calculated for twinned porphyroclasts and recrystallized grains (Fig. 10). The texture of the protomylonite (site 1 and 4) is characterized by a c-axis maximum, which is elongated along the periphery of the pole figure. The center of the maximum is oriented approximately normal to $\mathrm{S} 1$ with a clockwise component of rotation $\left(\sim 13^{\circ}\right)$ corresponding to a dextral shear sense with respect to S1. In the mylonite (site 6, Fig. 9) the c-axis maximum is normal to the SP. High pole densities lie within a range of $45^{\circ}$ along the periphery, symmetrically disposed with respect to the shear zone normal. In the center of the shear zone (site 7) high pole densities are found within a range of $25^{\circ}$ along the periphery of the pole figure inclined clockwise with respect to the shear zone normal, i.e. in the same rotation sense as the overall shear sense. The internal symmetry of the CIP and EBSD pole figures is approximately constant for all microstructural domains: elongated c-axis maxima and weak r-maxima normal to S1 (protomylonite) and to the shear plane 


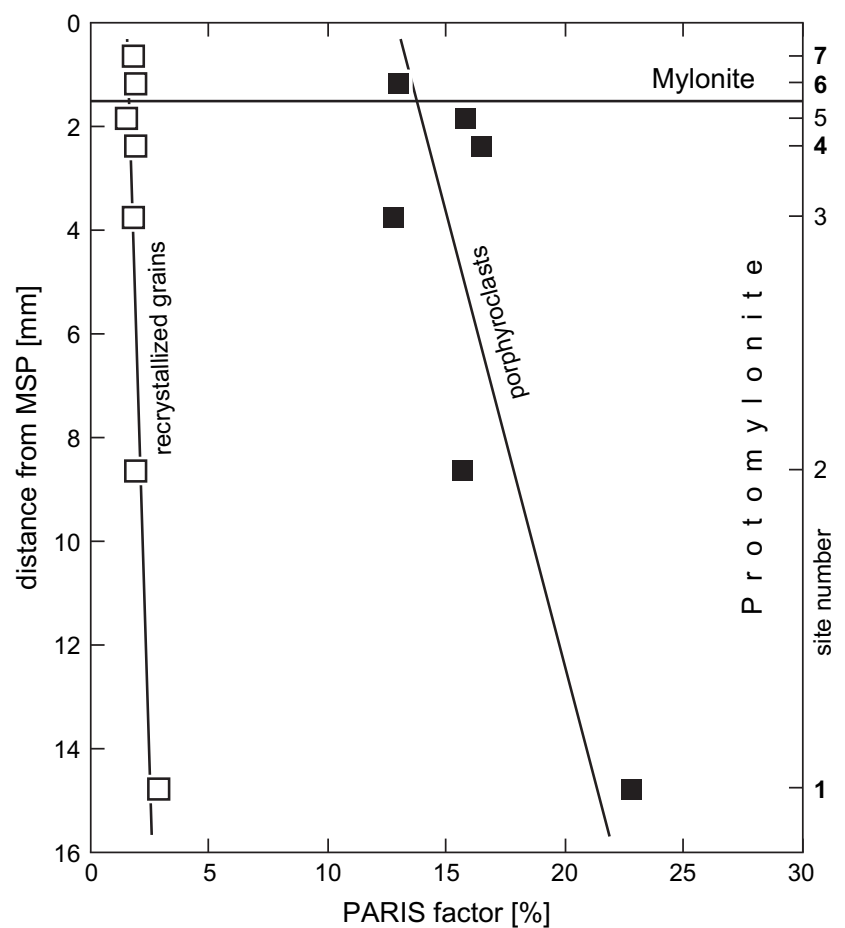

Fig. 8. PARIS factor for recrystallized grains (open squares) and porphyroclasts (filled squares). Site numbers $(1,4,6,7)$ on the right hand axis refer to sites analysed.

(SP) (mylonite). All sites are characterized by a-axes girdles parallel to S1. The a-axes single girdle of the mylonite is oriented parallel to the SP with one high density region close to the shear direction.

\section{Discussion}

\subsection{Shear zone geometry and development}

There is a steep strain gradient in the investigated shear zone: the ratio of local shear strains from the center to the shear zone boundary is greater than 50: 1 (Fig. 2b). The question arises, whether this gradient is a consequence of a strain rate variation, which exists at the same time in different parts of the shear zone, or whether strain has evolved in different parts of the shear zone at different times.

A decrease in recrystallized grain size in the mylonites with respect to the protomylonite indicates a higher stress in the mylonite (see also below under "grain size distributions"). Stress compatibility does not allow different stresses to exist across or along a shear zone at the same time (Cobbold, 1977; Ranalli, 1987, p. 25; Ramsay and Lisle, 2005, p. 707). Thus, deformation cannot have taken place at different stresses simultaneously in the protomylonite and in the mylonite. The best explanation for the different grain sizes of recrystallized grains is that the deformation of the mylonite and the protomylonite has taken place consecutively.

The sequential deformation of outer protomylonite and inner mylonitic parts of the shear zone requires a thinning or widening of the shear zone with time. A widening is unlikely because the older inner parts of the shear zone are rarely preserved in such cases (Type I shear zones; Means, 1995). Type I shear zones also tend to show flat strain profiles and abrupt strain gradients at their margins (Hull, 1988; Mitra, 1992; Means, 1995) instead of sigmoidal foilation trends as observed
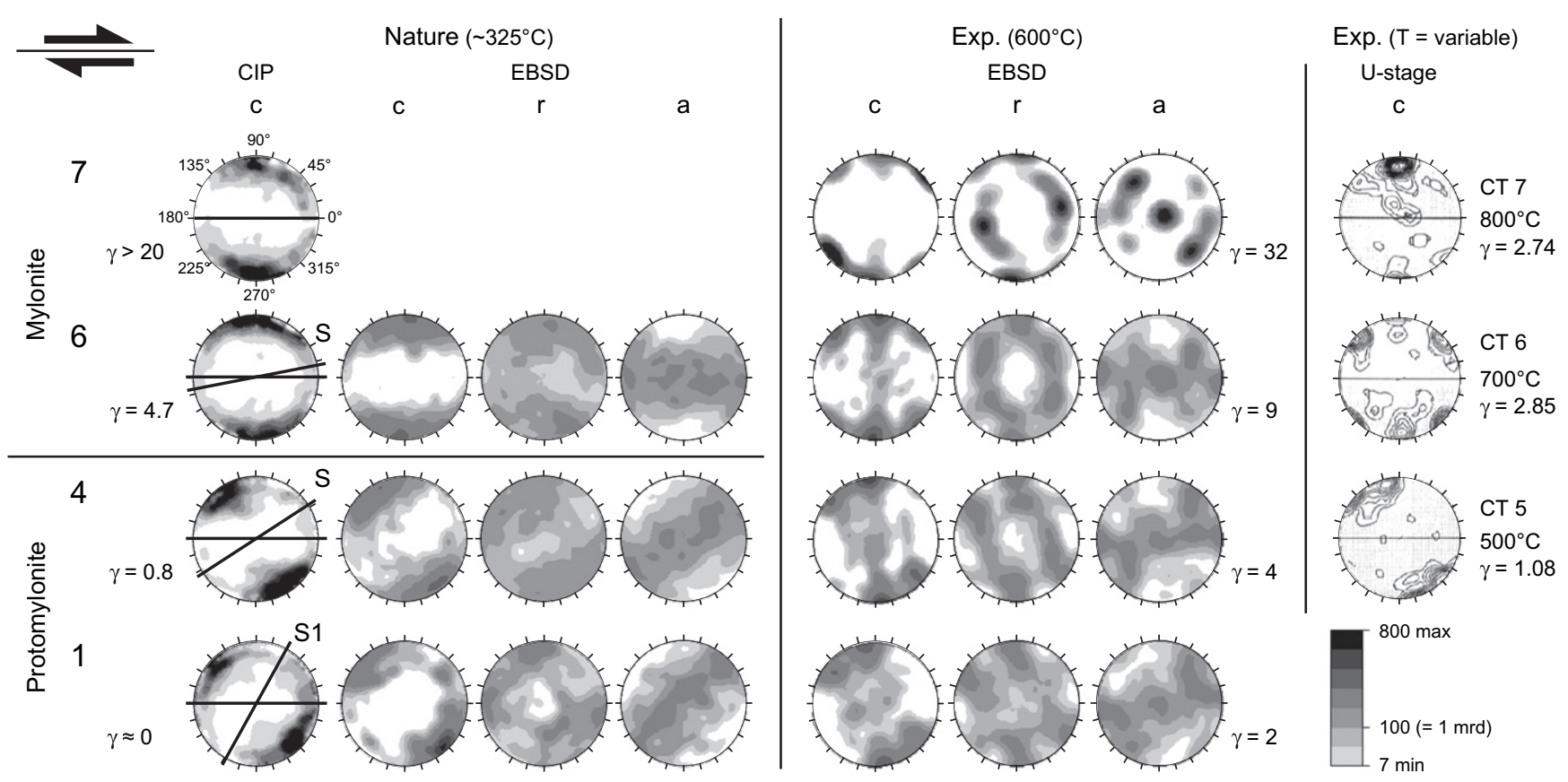

Fig. 9. Crystallographic preferred orientation (CPO) of the natural shear zone (left) determined by CIP and EBSD, CPO of experimentally deformed Carrara Marble (Barnhoorn et al., 2004) (center), c-axis pole figures (right) of experimentally deformed Carrara marble (Schmid et al., 1987). Dextral sense of shear applies to all pole figures. Inclined lines in CIP pole figures mark the orientation of the progressively rotated S1-foliation (S). Contours of CIP pole figures are 0.5 times uniform, for contours of EBSD pole figures see logarithmic scale, where $100=1$ m.r.d.; contours of Carrara marble pole figures are 1.0 times uniform. For pole figure maxima, see text. 


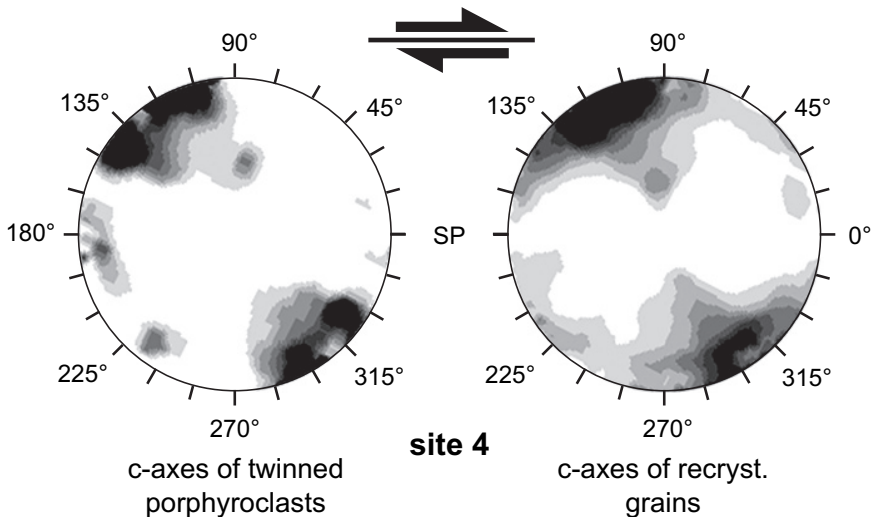

Fig. 10. Separate c-axis pole figures of twinned porphyroclasts (left) and recrystallized grains (right) of site 4 determined by CIP.

here. Thinning of the shear zone is most likely, i.e. deformation has ceased in the outer parts of the shear zone, where earlier microstructures are preserved. The thinning most likely implies a weakening of the shear zone material by, e.g., geometric weakening as a consequence of the texture development (e.g. White and Knipe, 1978; Rutter, 1999), although localization of deformation may also take place during hardening at certain conditions (Hobbs et al., 1990).

\subsection{D1 and D2 deformation}

There is no marble with less than $30 \%$ recrystallized grains in the vicinity of the shear zone in the outcrop, which is a few meters long, and we conclude that the D2 deformation associated with the shear zone formation has initially affected the entire rock volume on the outcrop scale, probably during the formation of the large scale D2-fold structure (Fig. 1). The increase in percentage of recrystallized grains within the $\sim 2 \mathrm{~mm}$ of the shear zone center is the result of shear localization, after which deformation of the rock on the outcrop scale has more or less ceased.

We do not associate the partial recrystallization with the D1 deformation because: (1) the local regional geology clearly indicates that the shear zone is a D2 shear zone; and (2) D1 deformation is followed by pervasive annealing, which obliterates all dynamic microstructures (e.g. Molli et al., 2000).

\subsection{Deformation temperature}

Our result of a deformation temperature of about $325^{\circ} \mathrm{C}$ agrees well with other D1 and D2 temperature determinations made for the region: For D1, a gradual decrease from West to East from 420 to $370{ }^{\circ} \mathrm{C}$ and for D2, a decrease from East to West from 430 to $295^{\circ} \mathrm{C}$ has been determined (Molli et al., 2000). The shear zone discussed here is located in the central part of the Alpi Apuane; the calculated D2 temperature fits well into the general D2 temperature distribution of the region according to Molli et al. (2000). The range of measured temperatures is quite large $\left(115^{\circ} \mathrm{C}\right)$ and is a consequence of the uncertainty of the calcite-dolomite thermometer at low temperatures. Because of this uncertainty it is impossible to conclude whether the localized deformation in the center of the shear zone may be caused by small temperature fluctuations in the rock body with time (e.g. less than \pm 30 degrees).

\subsection{Grain size distributions}

The grain size peak which corresponds to the large volume of recrystallized grains shifts from a value of $\sim 35 \mu \mathrm{m}$ in the protomylonite to a value of $\sim 25 \mu \mathrm{m}$ in the mylonite (Fig. 5) and implies that the strain rate increased (higher stresses will produce higher strain rates) when the localization into the central $2 \mathrm{~mm}$ wide mylonites of the shear zone took place.

Applying the piezometer of Rutter (1995) for rotation recrystallization of calcite (which yields slightly higher stresses than that of Schmid et al. (1980) for rotation recrystallization), flow stresses for $25 \mu \mathrm{m}$ and $35 \mu \mathrm{m}$ grain sizes are $48 \mathrm{MPa}$ and $36 \mathrm{MPa}$, respectively. These estimates represent a minimum value of the stresses because some grain boundary migration is observed in the microstructures and the stress values for migration recrystallization are higher for a given grain size. Using the stresses from piezometry and the calculated deformation temperature $\left(325^{\circ} \mathrm{C}\right)$ of the shear zone we can make a few crude strain rate estimates from flow laws by Walker et al. (1990) for dislocation creep (stress exponent $n=3.3$ and grain size exponent $m=-1.3$ ). Strain rates as fast as $1.4 \times 10^{-11} \mathrm{~s}^{-1}$ are predicted at the center of the shear zone and $3.4 \times 10^{-12} \mathrm{~s}^{-1}$ in the protomylonite. To achieve a total shear strain of $\gamma=20$ (center of the shear zone), about 45,000 years would be required. The strain rate ratio for protomylonite to mylonite (for $35 \mu \mathrm{m}$ to $25 \mu \mathrm{m}$ grain size the strain rate ratio is $1: 4.1)$ is smaller than the corresponding 1: 50 shear strain ratio, and is consistent with the conclusion made above that deformation selects a region where it is localized at a higher shear strain rate (smaller grain size, center of the shear zone) and abandons the rest of the rock because the different strain rates alone are not sufficient to produce the total strain gradient.

\subsection{Preferred orientation of grain boundaries and of grain long axes}

The orientations of 2-D (grain surface) features from the natural shear zone are similar to those of the samples from the experimental study of Schmid et al. (1987). The protomylonite (site 4) and the mylonite (site 6 and 7) can be compared to experimentally deformed Solnhofen limestone (ST2, ST5; Schmid et al., 1987, their Fig. 25) with an orthorhombic symmetry. The anisotropy of grain shape fabrics increases with increasing strain (site 4 and 6, Figs. 5 and 6) and decreases at the highest shear strain and complete recrystallization (site 7). The reason for the decrease is the complete disappearance of highly elongate pophyroclasts due to recrystallization because recrystallized grains are less elongate than deformed precursors and partially recrystallized pophyroclasts.

Separate PAROR (grain long axes) analyses for porphyroclasts and recrystallized grains reveal distinct rotational behaviour of recrystallized grains and porphyroclasts, especially for 
site 1 (Fig. 7), where the orientation of the long axes of recrystallized grains corresponds to the initial stretching direction of the period of deformation and recrystallization $\left(45^{\circ}\right.$ to the SP). From site 1 to site 4 the preferred orientation of recrystallized grains rotates from $33^{\circ}$ to $23^{\circ}$ in a clockwise sense (faster than the finite stretching direction as indicated by the foliation (Fig. 7). The cause of this rotation remains unclear. The results from site 6 and 7, which are $100 \%$ recrystallized, represent a continuation of rotation with particle long axes preferred orientation of $23^{\circ}$ and $8^{\circ}$.

\subsection{Shape factors (PARIS factors)}

A major problem in analyzing natural microstructures is the effect of post-deformational annealing of a microstructure. In the case of the studied example, dynamic microstructural features such as undulatory extinction, subgrains and lobate grain boundaries are still ubiquitous. We therefore assume only a minor influence of annealing on microstructure and texture.

Bulk PARIS factors (which are used as shape descriptors) of the entire microstructures (old grains and recrystallized grains combined) of naturally deformed Carrara marble in Molli and Heilbronner (1999) are $1.8 \%$ and $2.3 \%$ for completely recovered white marble, and up to $24 \%$ for the dynamically recrystallized ones $(\sim 50 \%$ recrystallization). The PARIS factors of the porphyroclasts of the shear zone in this study are $\sim 20 \%$, a value which coincides well with the dynamically recrystallized case of Molli and Heilbronner (1999), so that strong annealing of the microstructure (after D2) can be excluded.

The observation that the subgrains in the porphyroclasts are of the same size as the surrounding recrystallized grains indicates that subgrain rotation is the dominant recrystallization mechanism. The shape fabrics reflect the following process: With increasing shear strain the more lobate porphyroclasts (high PARIS factors) continue to recrystallize at their boundaries by subgrain rotation. They become less lobate during recrystallization, as indicated by a decreasing PARIS factor (Fig. 8). In contrast, the recrystallized grains (constant low PARIS factors) more or less maintain their equant shape with increasing strain. Thus, during the development of core-mantle structures the grains show a trend towards more convex and less lobate shapes.

\subsection{Texture development and dominant slip systems}

Textures with a pronounced c-axis maximum normal or slightly inclined to the main foliation have been described previously in natural calcite tectonites (e.g. Turner and Weiss, 1963; de Bresser, 1989; Ratschbacher et al., 1991; Erskine et al., 1993; Lafrance et al., 1994; Busch and Van der Pluijm, 1995; Bestmann et al., 2000; Trullenque et al., 2006). They are typical for D1-structures in the Alpi Apuane (Molli et al., 2000). Sites 1 and 4 have their c-axis maximum almost normal to the $\mathrm{S} 1$ foliation (c-axis maximum inclined $77^{\circ}$ to $\mathrm{S} 1$ in site 1; c-axis maximum inclined $85^{\circ}$ to $\mathrm{S}$ in site 4 ; Fig. 9) and we interpret the textures of porphyroclasts of site 1 of the protomylonite as relict D1 textures. Subordinate recrystallization during D2 accompanied by some modification of grain boundary configuration has not modified the textures much because shape fabrics change faster than textures (Stünitz, 1991). It is likely that the textures have formed by basal $\langle\mathrm{a}\rangle$ slip (Bestmann et al., 2000) and/or $\mathrm{r}^{-}\langle 20 \overline{2} \overline{1}\rangle$ slip, two main slip systems in calcite (de Bresser and Spiers, 1993, 1997; Erskine et al., 1993; Barnhoorn et al., 2004; Trullenque et al., 2006) as the dominant slip systems.

From site 1 to 4 the c-axis maxima rotate in an anticlockwise sense with respect to the original foliation (layering). A large contribution to the $\mathrm{CPO}$ comes from porphyroclasts. As can be seen from Fig. 10, the c-axis maximum consists of 2 separate maxima. The left-hand one is consistent with a twinning orientation of c-axes. Twinning is more prominent in the D2-deformed porphyroclasts than in site 1 . The position of the other maximum of the porphyroclast-CPO is consistent with an antithetic rotation of c-axes predicted by Taylor models for $\mathrm{r}^{-}$and $\mathrm{f}\langle 20 \overline{2} \overline{1}\rangle$ slip (Wenk et al., 1987; Wenk, 2002) and as found in experiments (Wagner et al., 1982; Casey et al., 1998; Barnhoorn et al., 2004). Thus, the early stages of progressive D2-deformation produce a small amount of dynamically recrystallized grains and show a texture development consistent with Taylor theory during the transition of a D1 to D2 texture.

The c-axes of the recrystallized grains in site 4 are rotated in a clockwise sense (which is the sense of D2 shear) with respect to the porphyroclasts (Fig. 10). Such a rotation brings them closer to an ideal orientation for basal $\langle a\rangle$ slip with respect to the SP, consistent with the clockwise rotation of the recrystallized grains' long axis with increasing strain, as discussed above (Fig. 7). Thus, the slight rotation and amplification of the c-axis maximum of a pre-existing basal $\langle\mathrm{a}\rangle$ texture may be caused by the replacement (or gradual superposition) of the S1-originated basal $\langle\mathrm{a}\rangle$ texture by a rotation of the c-axis maximum caused by dynamic recrystallization. In this shear zone, dynamic recrystallization occurs through subgrain rotation accompanied by some grain boundary migration. For a basal slip plane and r-slip-planes oriented favorably for slip, tilt walls are expected to produce a dispersion of the c-axis maximum along the periphery of the pole figure. If kinematically favorably oriented grains grow by boundary migration and unfavorably oriented grains are progressively consumed, the effect of the recrystallization will be a rotation of the c-axis maximum in a synthetic sense with respect to the overall shear sense.

A synthetic rotation with the sense of shear during recrystallization is observed experimentally by Casey et al. (1998), Pieri et al. (2001a), and Barnhoorn et al. (2004). This behavior is in contrast to that of the porphyroclasts (which rotate according to a Taylor model). Modelling of such a texture evolution involving dynamic recrystallization produces such an "easy slip" orientation if nucleation is dominant (Wenk and Tomé, 1999; Lebensohn et al., 1998; Wenk et al., 1987).

Twinning rotates the parts of the porphyroclasts into an orientation, which is favored by $\mathrm{r}^{-}\langle 20 \overline{2} \overline{1}\rangle$ slip. In an e-twinning orientation, additional $\mathrm{r}\langle 20 \overline{2} \overline{1}\rangle$ slip may occur. The activity of the $r\langle 20 \overline{2} \overline{1}\rangle$ slip system is supported by the r-pole figure, 
determined by EBSD, which shows a r-maximum approximately normal to the SP (Fig. 9).

The trend of a reorientation of grains by dominantly subgrain rotation continues in the transition to site 6 , where most of the grains are recrystallized (Figs. $2 \mathrm{~b}$ and 3 ). The recrystallization-dominated texture shows a broad c-axis maximum approximately normal to the shear plane (Fig. 9). Such textures have been observed in experiments by Schmid et al. (1987), Casey et al. (1998) and Barnhoorn et al. (2004) for high strains. The broad maximum can be explained by a combination of orientations favorable for $\mathrm{r}^{-}\langle 20 \overline{2} \overline{1}\rangle$ and basal 〈a slip (Barnhoorn et al., 2004; Bestmann et al., 2000; Schmid et al., 1987). An r-maximum normal to the shear plane and an $\langle a\rangle$ girdle parallel to the shear plane are documented in the EBSD data of site 6 (Fig. 9).

In the center of the mylonite (site $7 ; 100 \%$ recrystallized grains) the texture is characterized by a main single c-axis maximum and a weaker distribution spread in a clockwise sense from the maximum (Fig. 9). The single maximum c-axis textures have been observed in natural mylonites (Busch and Van der Pluijm, 1995; Bestmann et al., 2000) and in experiments (Schmid et al., 1987; Pieri et al., 2001a; Barnhoorn et al., 2004) and are attributed to dominant basal $\langle a\rangle$ slip. Some $\mathrm{r}^{-}$and $\mathrm{f}^{-}\langle 2 \overline{2} 01\rangle$ slip may be inferred from the clockwise spread of the c-axes (Trullenque et al., 2006; Lafrance et al., 1994). Thus, the highest strain texture of D2 deformation is ore or less restored to the same texture type as the starting D1 texture with a dominant c-axis maximum normal to the foliation.

\subsection{Comparison with other natural shear zones and experimental data}

Many studies of natural calcite mylonites (Behrmann, 1983; Dietrich and Song, 1984; de Bresser, 1989; Ratschbacher et al., 1991; Lafrance et al., 1994; Bestmann et al., 2000) show textures which are characterized by c-axis distributions with a single maximum normal to the shear plane or slightly inclined to its normal. The shear plane corresponds approximately to the mesoscopically visible mylonite foliation.

Experimental studies on calcite marbles in the dislocation creep field and computer simulations using Taylor theory yield orthorhombic textures with a c-axis point maximum normal to the flattening plane for a pure shear path and a c-axis point maximum oblique to the shear plane rotated antithetically to the shear sense (monoclinic symmetry) for simple shear path deformation (Wagner et al., 1982; Wenk et al., 1986, 1987; Wenk, 2002). Several authors infer partitioning of large components of pure shear deformation into calcite rocks with a c-axis maximum normal to the mylonitic foliation (de Bresser, 1989; Erskine et al., 1993; Ratschbacher et al., 1991). In our case, the shape fabrics, overall geometry of the shear zone, and texture clearly document simple shear dominated deformation, during which a single c-axis maximum normal to the shear plane with minor components of synthetically rotated c-axes develops. Other examples of such textures and kinematics are documented in the literature (Bestmann et al., 2000;
Busch and Van der Pluijm, 1995; Lafrance et al., 1994; de Bresser, 1989; Trullenque et al., 2006).

The deformation temperature of D2 (approximately $325^{\circ} \mathrm{C}$ ) is about $70{ }^{\circ} \mathrm{C}$ lower than the inferred deformation temperature of D1 (Molli et al., 2000). The development of the same texture type during D2 shearing as during D1 suggests that the same slip systems and recrystallization mechanisms have been active as in D1 deformation. The smaller grain size of the D2 microstructure compared to D1 is consistent with the lower temperature of deformation at similar rates of deformation. The deformation temperature is in the same range as the samples of Bestmann et al. (2000), where similar textures are described and higher than in the examples of de Bresser (1989), for which a transition between high and low temperature texture types is inferred.

\subsection{Summary of texture development}

For the texture development across a natural shear zone we consider a process in successive stages with progressively increasing strain magnitude and recrystallization (Fig. 11). First, at low finite strain, texture development is dominated by dislocation glide and can be described by twinning and Taylor theory. As a result of lattice rotation during twinning, more crystals obtain an orientation which is favored by $r^{-}\langle 20 \overline{2} \overline{1}\rangle$ slip (Fig. 11). Progressive subgrain rotation and some grain boundary migration promote the rotation of the recrystallized grains into an orientation with their basal plans parallel to the SP (Fig. 11; point 2). The new orientation is favorable for basal

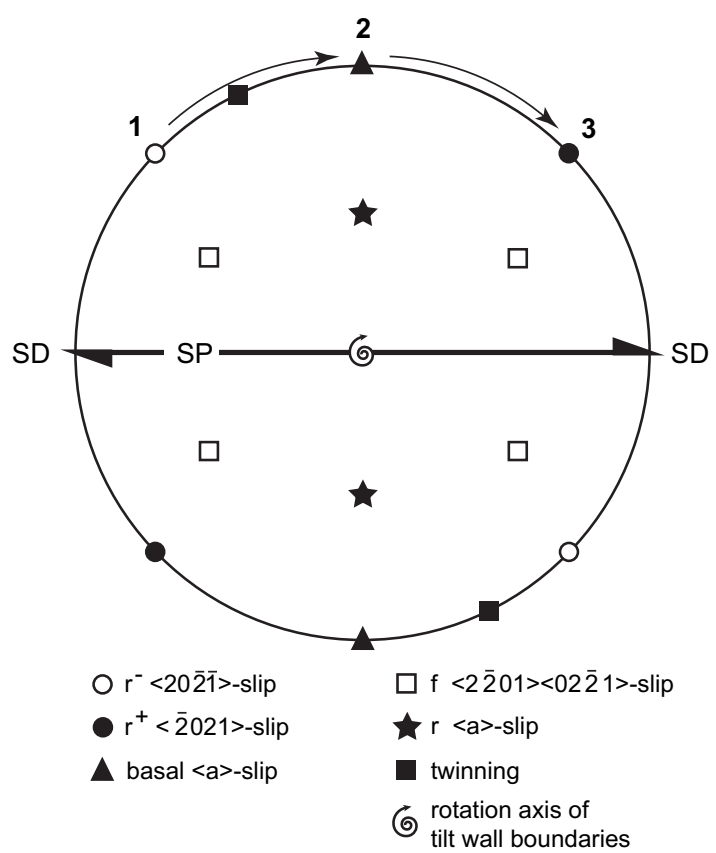

Fig. 11. Schematic presentation of ideal c-axis orientations for different slip systems in a calcite crystal. The slip plane of the given slip system is oriented parallel to the shear plane (SP) and the slip direction parallel to the shear direction (SD) (easy slip conditions). Arrows from point 1 to 2 to 3 indicate the envisaged schematic development of the preferred c-axis orientation with increasing shear strain as discussed in the text. 
〈a slip. Further subgrain rotation may lead to an orientation of grains favorable for $\mathrm{r}^{+}\langle\overline{2} 021\rangle$-slip (Fig. 11; point 3 ). The activity of dislocations in the operative slip system in combination with subgrain rotation recrystallization leads to the formation of tilt wall boundaries. Under conditions of easy slip progressive subgrain rotation recrystallization may translate a crystal orientation at position 1 into position 2 and possibly 3 (Fig. 11). This mechanism may change a pre-existing texture of a different orientation into a texture typical of basal $\langle a\rangle$-slip and subordinate $\mathrm{r}^{-}\langle 20 \overline{2} \overline{1}\rangle$ slip.

\section{Conclusions}

A small shear zone in Carrara marble in the Alpi Apuane tectonic window displays a finite strain gradient, which is interpreted to be caused by a localization of deformation with time in the central part, so that the outer parts of the shear zone preserve earlier stages of the deformation history. Calcite-dolomite thermometry demonstrates that progressive deformation took place at more or less constant temperature. During the extensional stage of the Apuane deformation, the shear zone formed at a temperature of $325^{\circ} \mathrm{C} \pm 30^{\circ} \mathrm{C}$.

Due to the sequential deformation of different parts of the shear zone, the different microstructures, shape fabrics, and textures measured across the shear zone represent progressive stages in the evolution of the calcite fabric during mylonitization.

The grain size of recrystallized grains during dynamic rotation recrystallization decreases from $\sim 35$ in the protomylonite to $\sim 25 \mu \mathrm{m}$ in the center of the shear zone corresponding to stresses of 36 and $48 \mathrm{MPa}$, respectively. Inferred strain rates vary between $3.4 \times 10^{-12} \mathrm{~s}^{-1}$ in the protomylonite and $1.4 \times 10^{-11} \mathrm{~s}^{-1}$ in mylonite in the center of the shear zone.

The elongation and shapes of calcite grains vary with progressive deformation: porphyroclasts are lobate, have generally concave boundaries and become progressively elongated during shearing, whereas recrystallized grains are round, convex in shape and far less elongated.

The textures outside the shear zone represent a texture indicative of basal $\langle a\rangle$ slip. Initially, the pre-deformational c-axis orientation rotates in a sense consistent with Taylor theory. With increasing finite shear strain, the texture is modified by dynamic recrystallization. Progressive subgrain rotation disperses the c-axes normal to the foliation. Synthetic rotation with the sense of shear appears to favor these c-axis orientations during recovery and preferential removal of kinematically unfavorably oriented grains by grain boundary migration. A single c-axis maximum oriented normal to the shear plane is the highest strain texture. In the central mylonitic, completely recrystallized, parts of the shear zone with the highest finite shear strain, the single c-axis texture is accompanied by a synthetically rotated c-axis distribution consistent with $r^{-}\langle 20 \overline{2} \overline{1}\rangle$ slip. The differences in texture and shape fabrics are caused by a progressive increase in the volume fraction of dynamically recrystallized grains with increasing shear strain from less than $40 \%$ outside the shear to $100 \%$ in the shear zone center. As the increasing volume fraction of recrystallized grains correlates with strain magnitude, a finite strain-dependence of the texture development is observed.

\section{Used software}

[1] Digital imaging software (CIP, StripStar, Ime d' Ouline, SURPOR and PAROR): http://www.unibas.ch/earth/micro/. [2] NIH-Image, http://rsb.info.nih.gov/nih-image/download. html.

\section{Acknowledgements}

We wish to thank Stefan Schmid and Hans De Bresser for many fruitful and stimulating discussions on calcite deformation. Critical comments and many suggestions by Karsten Kunze and Marco Herwegh and very constructive reviews by Joe White an anonymous reviewer have improved the manuscript substantially. We also thank Willi Tschudin, who prepared excellent ultra-thin sections, without which this study would have been impossible. Thank you also to the people of the EMEZ at the ETH Zürich who have supported us during the EBSD measurements. The Swiss National Science Foundation grants NF 20-49562.96, NF 2000-055420.98 and NF 2000-063662.00 are gratefully acknowledged.

\section{References}

Anovitz, L.M., Essene, E.J., 1987. Phase equilibria in the system CaCO3MgCO3-FeCO3. Journal of Petrology 28 (2), 389-414.

Barnhoorn, A., Bystricky, M., Burlini, L., Kunze, K., 2004. The role of recrystallization on the deformation behaviour of calcite rocks: large strain torsion experiments on Carrara marble. Journal of Structural Geology 26, 885-903.

Behrmann, J., 1983. Microstructure and fabric transitions in calcite tectonites from the Sierra Alhamilla (Spain). Geologische Rundschau 72 (2), 605-618.

Bestmann, M., Kunze, K., Matthews, A., 2000. Evolution of a calcite marble shear zone complex on Thassos Island, Greece: microstructural and textural fabrics and their kinematic significance. Journal of Structural Geology $22,1789-1807$

Boccaletti, M., Coli, M., Gosso, G., 1982. Strutture di interferenza a scala megascopica nel settore Nord delle Alpi Apuane. Memorie Società Geologica Italiana 24, 289-292.

Burg, J.-P., Wilson, C.J.L., 1987. Deformation of two phase systems with contrasting rheologies. Tectonophysics 135, 199-205.

Burkhard, M., 1990. Ductile deformation mechanisms in micritic limestones naturally deformed at low temperatures $\left(150-350{ }^{\circ} \mathrm{C}\right)$. In: Knipe, R.J., Rutter, E.H. (Eds.), Deformation Mechanisms, Rheology and Tectonics. Geological Society, London, Special Publications, vol. 54, pp. 241-257.

Busch, J.P., Van der Pluijm, B.A., 1995. Calcite textures, microstructures and rheological properties of marble mylonites in the Bancroft shear zone, Ontario, Canada. Journal of Structural Geology 17 (5), 667-688.

Carmignani, L., 1985. Carta geologico-strutturale delle Alpi Apuane, Foglio Nord, Litografia Artistica Cartografica, Firenze, scala 1:25.000.

Carmignani, L., Giglia, G., 1979. Large scale reverse $\ll$ drag folds $\gg$ in the late alpine building of the Apuane Alps (N. Apennines). Atti della Società Toscana di Scienze Naturali, Memorie 86, 109-125.

Carmignani, L., Kligfield, R., 1990. Crustal extention in the Northern Apennines: the transition from compression to extension in the Alpi Apuane core complex. Tectonics 9 (6), 1275-1303. 
Carmignani, L., Decandia, F.A., Fantozzi, P.L., Lazzarotto, A., Liotta, D., Meccheri, M., 1994. Tertiary extensional tectonics in Tuscany (Northern Apennines, Italy). Tectonophysics 238, 295-315.

Casey, M., Kunze, K., Olgaard, D.L., 1998. Texture of Solnhofen Limestone deformed to high strains in torsion. Journal of Structural Geology 20 (2-3), 255-267.

Cobbold, P.R., 1977. Description and origin of banded deformation structures. II. Rheology and the growth of banded perturbations. Canadian Journal of Earth Sciences 14, 2510-2523.

Coli, M., 1989. Litho-structural assemblage and deformation history of "Carrara marble". Bollettino della Società Gelologica Italiano 108, 581-590.

de Bresser, H.J.P., 1989. Calcite c-axis textures along the Gavarnnie thrust zone, Central Pyrenees. Geologie en Mijnbouw 68, 367-375.

de Bresser, H.J.P., Spiers, C.J., 1993. Slip systems in Clacite single crystals deformed at 300-800 ${ }^{\circ} \mathrm{C}$. Journal of Geophysical Research 98, 6397-6409.

de Bresser, H.J.P., Spiers, C.J., 1997. Strength characteristics of the r, f, and c slip systems in calcite. Tectonophysics $272,1-23$.

Dietrich, D., Song, H., 1984. Calcite fabrics in a natural shear environment, the Helvetic nappes of western Switzerland. Journal of Structural Geology 6 (1/2), 19-32.

Erskine, B.G., Heidelbach, F., Wenk, H.-R., 1993. Lattice preferred orientations and microstructures of deformed Cordilleran marbles: correlation of shear indicators and determination of strain path. Journal of Geology 15 (9/10), 1189-1205.

Guillopé, M., Poirier, J.-P., 1979. Dynamic recrystallization during creep of single-crystalline halite; an experimental study. Journal of Geophysical Research 84, 5557-5567.

Heilbronner, R., 2000. Automatic grain boundary detection and grain size analysis using polarization micrographs or orientation images. Journal of Structural Geology 22, 969-981.

Heilbronner, R., Bruhn, D., 1998. The influence of three-dimensional grain size distributions on the rheology of polyphase rocks. Journal of Structural Geology 20 (6), 695-705.

Heitzmann, P., 1987. Calcite mylonites in the Central Alpine "root zone". Tectonophysics 135, 207-215.

Herwegh, M., Handy, M.R., 1998. The origin of shape preferred orientations in mylonite: inferences from in-situ experiments on polycrystalline norcamphor. Journal of Structural Geology 20 (6), 681-694.

Hobbs, B.E., Muhlhaus, H.B., Ord, A., 1990. Instability, softening, and localization of deformation. Geological Society, London, Special Publications, vol. 54, pp. 143-166.

Hull, J., 1988. Thickness-displacement relationships for deformation zones. Journal of Structural Geology 10, 431-435.

Kennedy, L.A., White, J.C., 2001. Low-temperature recrystallization in calcite: Mechanisms and consequences. Geology 29 (11), 1027-1030.

Kligfield, R., Hunziker, J., Dallmeyer, R.D., Schamel, S., 1986. Dating of deformation phases using $\mathrm{K}-\mathrm{Ar}$ and $40 \mathrm{Ar} / 39 \mathrm{Ar}$ techniques: results from the Northern Apennines. Journal of Structural Geology 8 (7), 781-798.

Lafrance, B., White, J.C., Williams, P.F., 1994. Natural calcite c-axis fabrics: an alternative interpretation. Tectonophysics $229,1-18$.

Lebensohn, R.A., Wenk, H.-R., Tomé, C.N., 1998. Modelling deformation and recrystallization. Acta Materialia 46, 2683-2693.

Matthews, A., Lieberman, J., Avigad, D., Garfunkel, Z., 1999. Fluid-rock interaction and thermal evolution during thrusting of an Alpine metamorphic complex (Tinos island, Greece). Contributions to Mineralogy and Petrology $135,212-224$.

Means, W.D., 1983. Microstructure and micromotion in recrystallization flow of octochloropropane, a first look. Geologische Rundschau 72, 511-528.

Means, W.D., 1995. Shear zones and rock history. Tectonophysics 247, $157-160$.

Mitra, G., 1992. Deformation of granitic basement rocks along fault zones at shallow to intermediate crustal levels. In: Mitra, S., Fisher, G.W. (Eds.), Structural Geology of Fold and Thrust Belts. Johns Hopkins University Press, Baltimore, pp. 123-144.

Molli, G., Heilbronner, R., 1999. Microstructures associated with static and dynamic recrystallization of Carrara marble (Alpi Apuane, NW Tuscany, Italy). Geologie en Mijnbouw 78, 119-126.
Molli, G., Conti, P., Giorgettil, G., Meccheri, M., Oesterling, N., 2000. Microfabric study on the deformational and thermal history of the Alpi Apuane marbles (Carrara marbles), Italy. Journal of Structural Geology 22, 1809-1825.

Panozzo, R., 1983. Two-dimensional analysis of shape-fabric using projections of digitized lines in a plane. Tectonophysics 95, 279-294.

Panozzo, R., 1984. Two-dimensional strain from the orientation of lines in a plane. Journal of Structural Geology $6(1 / 2), 215-221$.

Panozzo, R., Hürlimann, H., 1983. A simple method for the quantitative discrimination of convex and convex-concave lines. Microscopica Acta 87 (2), 169-176.

Panozzo Heilbronner, R., Pauli, C., 1993. Integrated spatial and orientation analysis of quartz c-axis by computer-aided microscopy. Journal of Structural Geology 15 (3-5), 369-382.

Pieri, M., Burlini, L., Kunze, K., Stretton, I., Olgaard, D.L., 2001a. Rheological and microstructural evolution of Carrara marble with high shear strain: results from high temperature torsion experiments. Journal of Structural Geology 23, 1393-1413

Pieri, M., Kunze, K., Burlini, L., Stretton, I., Olgaard, D.L., Burg, J.-P., Wenk, H.-R., 2001b. Texture development of calcite by deformation and dynamic recrystallization at $1000 \mathrm{~K}$ during torsion experiments of marble to large strains. Tectonophysics 330, 119-140.

Poirier, J.-P., Guillopé, M., 1979. Deformation induced recrystallization of minerals. In: Nicolas, A., Darot, M., Willaime, C. (Eds.), Mecanismes de deformation des mineraux et des roches. Masson, Paris, pp. 67-74.

Powell, R., Condliffe, D.M., Condliffe, E., 1984. Calcite-dolomite geothermometry in the system $\mathrm{CaCO} 3-\mathrm{MgCO} 3-\mathrm{FeCO} 3$ : an experimental study. Journal of Metamorphic Geology 2, 33-41.

Ramsay, J., 1967. Folding and Fracturing of Rocks. McGraw-Hill, New York.

Ramsay, J., Graham, R.H., 1970. Strain variation in shear belts. Canadian Journal of Earth Science 7, 786-813.

Ramsay, J.G., Lisle, R.J., 2005. The Techniques of Modern Structural Geology. Applications of Continuum Mechanics in Structural Geology. Academic Press, London.

Ranalli, G., 1987. Rheology of the Earth. Allen \& Unwin, Boston.

Ratschbacher, L., Wenk, H.-R., Sintubin, M., 1991. Calcite textures: examples from nappes with strain-path partitioning. Journal of Structural Geology 13 (4), 369-384.

Rutter, E.H., 1995. Experimental study of the influence of stress, temperature, and strain on the dynamic recrystallization of Carrara marble. Journal of Geophysical Research 100 (B12), 24,651-24,663.

Rutter, E.H., 1999. On the relationship between the formation of shear zones and the form of the flow law for rocks undergoing dynamic recrystallization. Tectonophysics 303, 147-158.

Rutter, E.H., Casey, M., Burlini, L., 1994. Preferred crystallographic orientation development during plastic and superplastic flow of calcite rocks. Journal of Structural Geology 16 (10), 1431-1446.

Schmid, S.M., 1975. The Glarus overthrust: Field evidence and mechanical modal. Eclogae Geologicae Helvetiae 68/2, 247-280.

Schmid, S.M., 1981. Laboratory Experiments on Rheology and Deformation Mechanisms in Calcite Rocks and Their Application to Studies in the Field. Unpublished Habiliationsschrift, ETH Zürich.

Schmid, S.M., Paterson, M.S., Boland, J.N., 1980. High temperature flow and dynamic recrystallization in Carrara marble. Tectonophysics 65, 245-280.

Schmid, S.M., Panozzo, R., Bauer, S., 1987. Simple shear experiments on calcite rocks: rheology and microstructure. Journal of Structural Geology 9 (5/6), 747-778.

Sibson, R.H., 1977. Fault rocks and fault mechanisms. Journal of the Geological Society of London 133, 191-214.

Stünitz, H., 1991. Folding and shear deformation in quartzites, inferred from crystallographic preferred orientation and shape fabrics. Journal of Structural Geology 13, 71-86.

Trullenque, G., Kunze, K., Heilbronner, R., Stunitz, H., Schmid, S.M., 2006. Microfabrics of calcite ultramylonites as records of coaxial and noncoaxial deformation kinematics: examples from the Rocher de l'Yret shear zone (western Alps). Tectonophysics 424, 69-97.

Turner, F.J., Weiss, L.E., 1963. Structural Analysis of Metamorphic Tectonites. McGraw-Hill, New York.

Underwood, E.E., 1970. Quantitative Stereology. Addison-Wesley, London. 
Van der Pluijm, B.A., 1991. Marble mylonites in the Bancroft shear zone, Ontario, Canada: microstructures and deformation mechanisms. Journal of Structural Geology 13 (10), 1125-1135.

Wagner, F., Wenk, H.-R., Kern, H., Van Houtte, P., Esling, C., 1982. Development of preferred orientation in plane strain deformed limestone: experiment and theory. Contributions to Mineralogy and Petrolology 80 (2), 132-139.

Walker, A.N., Rutter, E.H., Brodie, K.H., 1990. Experimental study of grainsize sensitive flow of synthetic, hot-pressed calcite rocks. In: Knipe, R.J., Rutter, E.H. (Eds.), Deformation Mechanisms, Rheology and Tectonics. Geological Society, London, Special Publications, vol. 54, pp. 259-284.

Wenk, H.-R., 2002. Texture and anisotropy. In: Karato, S., Wenk, H.-R. (Eds.), Plastic Deformation of Minerals and Rocks. Reviews in Mineralogy and Geochemistry 51, 291-352.
Wenk, H.R., Tomé, C.N., 1999. Modeling dynamic recrystallisation of olivine aggregates deformed in simple shear. Journal Geophysical Research, B: Solid Earth and Planets 104 (11), 25,513-25,527.

Wenk, H.-R., Takeshita, T., Van Houtte, P., Wagner, F., 1986. Plastic anisotropy and texture development in calcite polycrystals. Journal of Geophysical Research 91 (B3), 3861-3869.

Wenk, H.-R., Takeshita, T., Bechler, E., Erskine, B.G., Matthies, S., 1987. Pure shear and simple shear calcite textures. Comparison of experimental, theoretical and natural data. Journal of Structural Geology 9 (5/6), $731-745$.

White, S.H., Knipe, R.J., 1978. Transformation- and reaction-enhanced ductility in rocks. Journal of the Geological Society of London 135, 513-516.

Wilson, C.J.L., 1981. Experimental folding and fabric development in multilayered ice. Tectonophysics 78, 139-159. 